Hydrol. Earth Syst. Sci., 15, 3217-3235, 2011

www.hydrol-earth-syst-sci.net/15/3217/2011/

doi:10.5194/hess-15-3217-2011

(c) Author(s) 2011. CC Attribution 3.0 License.

\title{
What do moisture recycling estimates tell us? Exploring the extreme case of non-evaporating continents
}

\author{
H. F. Goessling ${ }^{1,2}$ and C. H. Reick ${ }^{1}$ \\ ${ }^{1}$ Max Planck Institute for Meteorology, Hamburg, Germany \\ ${ }^{2}$ International Max Planck Research School on Earth System Modelling, Hamburg, Germany \\ Received: 30 March 2011 - Published in Hydrol. Earth Syst. Sci. Discuss.: 12 April 2011 \\ Revised: 14 October 2011 - Accepted: 19 October 2011 - Published: 25 October 2011
}

\begin{abstract}
Moisture recycling estimates are diagnostic measures that could ideally be used to deduce the response of precipitation to modified land-evaporation. Recycling estimates are based on moisture-budget considerations in which water is treated as a passive tracer. But in reality water is a thermodynamically active component of the atmosphere. Accordingly, recycling estimates are applicable to deduce the response to a perturbation only if other mechanisms by which evaporation affects climate do not dominate the response $-\mathrm{a}$ condition that has not received sufficient attention in the literature. In our analysis of what moisture recycling estimates tell us, we discuss two such additional mechanisms that result from water's active role. These are (I) local coupling, by which precipitation is affected locally via the thermal structure of the atmosphere, and (II) the atmospheric circulation, by which precipitation is affected on a large spatial scale.

We perform two global climate model experiments: One with and another without continental evaporation. By this extreme perturbation we test the predictive utility of a certain type of recycling measure, the "continental recycling ratio". Moreover, by such a strong perturbation the whole spectrum of possible responses shows up simultaneously, giving us the opportunity to discuss all concurrent mechanisms jointly.

The response to this extreme perturbation largely disagrees with the hypothesis that moisture recycling is the dominant mechanism. Instead, most of the response can be attributed to changes in the atmospheric circulation, while the contributions to the response by moisture recycling as well as local coupling, though noticeable, are smaller. By our case study it is not possible to give a general answer to the question posed
\end{abstract}

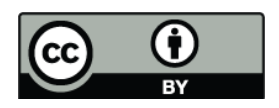

Correspondence to: H. F. Goessling (helge.goessling@zmaw.de) in the title, but it demonstrates that recycling estimates do not necessarily mirror the consequences of land-use change for precipitation.

\section{Introduction}

Source-target relations of passive atmospheric trace gases provide straightforward information on consequences for the target region from modified emissions at the source region. This concept is also at the bottom of a number of studies dealing with the transport of water over the continents. Realising that water is not a passive trace gas but an active constituent of the Earth's atmosphere, it appears that in this case the applicability of this concept crucially depends on the assumption that the atmospheric response following a hypothetical perturbation in evaporation is dominated by the "passive" effect evaporation exerts on the atmospheric moisture budget, i.e. by "moisture recycling". But water, existing in and transitioning between its different phases, strongly affects the atmospheric budgets of heat, momentum, and radiation. As a result, evaporation affects precipitation not only via moisture recycling (sometimes referred to as "direct coupling"), but also via local modification of the atmosphere's thermal structure ("local coupling", sometimes referred to as "indirect coupling" or "indirect recycling") and via its influence on the atmospheric large-scale circulation (Fig. 1). Accordingly, general statements about the predictive utility of recycling estimates that ignore possible implicit limitations should be treated with caution. One such statement is the following by van der Ent et al. (2010): "The magnitude of moisture recycling can be used as an indicator for the sensitivity of climate to land-use changes." We argue that the

Published by Copernicus Publications on behalf of the European Geosciences Union. 
(I) Moisture recycling

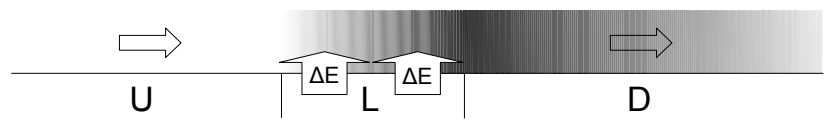

(II) Local coupling

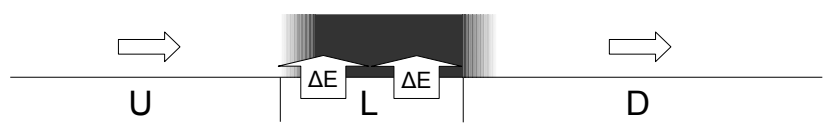

(III) Circulation

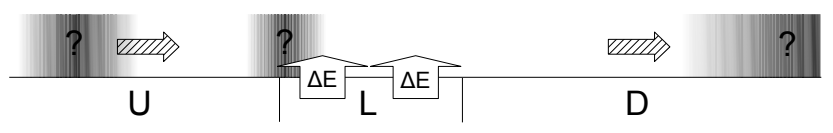

Fig. 1. Schematic of three mechanisms via which evaporation affects precipitation. The effect of each mechanism is shown isolated from the others. The arrows pointing to the right indicate the wind direction. The colour gradients indicate the regions where precipitation responds (either positively or negatively). $\mathrm{U}=$ upwind region, $\mathrm{L}=$ local region, $\mathrm{D}=$ downwind region, $\Delta E=$ imposed evaporation anomaly. (I) Moisture recycling: The precipitation response, caused by changes to the atmospheric moisture budget, grows gradually over the region of the imposed evaporation anomaly, then decays (slowly) over the downwind region. (II) Local coupling: The precipitation response, caused by changes to the thermal structure of the atmosphere, collocates with the imposed evaporation anomaly. A slight downwind shift is indicated because the structural change may need some time to develop. (III) Circulation: The precipitation response may occur anywhere, caused by changes to the 3-D large-scale atmospheric circulation (indicated by the hatching of the wind-arrows). While mechanism (I) accounts for the effect of $\Delta E$ on the vertically integrated atmospheric moisture budget, mechanisms (II) and (III) account for modified energetics that come along with $\Delta E$ (in particular changes in temperature).

conditions under which such a claim is valid have not yet been examined sufficiently.

A comprehensive specification of the conditions under which moisture recycling estimates can be used reliably to indicate the sensitivity of climate to land-use change is beyond the scope of the present study. Instead we make a first step in this direction by exploring the response of climate to a well-defined extreme perturbation. From the whole suite of recycling diagnostics, we concentrate on one particular called "continental recycling ratio", that is the fraction of moisture in precipitation that stems from continental evaporation (Bosilovich et al., 2002; Yoshimura et al., 2004; van der Ent et al., 2010). For this measure the perturbation considered in our simulations is a natural choice to test its predictive utility concerning the response of precipitation to changes in surface evaporation.
Our investigation proceeds as follows. We first estimate continental recycling ratios from the climate data we obtain from a global model experiment that represents present-day conditions. In a second model experiment we completely suppress continental evaporation and compare the simulated response with the response that is "predicted" by the continental recycling ratios. Finally, we analyse in more detail the contributions from changes in the atmospheric circulation and from local coupling to the overall response.

As the terms "local coupling" and "large-scale circulation" imply, these mechanisms act on different spatial scales. It thus seems reasonable that the relative importance of the three processes (including moisture recycling) depends on the spatial scale of the perturbation. While local coupling acts already on comparatively small spatial scales, effects from moisture recycling and from changes in the large-scale circulation are expected to be relevant only if the spatial scale of the perturbation is sufficiently large. By suppressing continental evaporation globally, which is an extreme land-surface modification, we ensure that all mechanisms contribute to the response simultaneously - a desirable condition for a case study that is intended to demonstrate that in general several different mechanisms contribute to the response to changes in evaporation, and that a single mechanism like moisture reycling thus can only be employed to deduce the response if other mechanisms are of minor importance.

The paper is structured as follows. In Sect. 2 we review three mechanisms through which evaporation affects climate (Sects. 2.1-2.3) and discuss at what spatial scales they act (Sect. 2.4). In Sect. 3 we describe the climate model experiments (Sect. 3.1) and the method we apply to quantify continental moisture recycling in the reference experiment (Sect. 3.2). In Sect. 4 we present the resulting continental recycling ratios. In Sect. 5 we analyse in how far the response can be attributed to moisture recycling (Sect. 5.1), to the atmospheric circulation (Sect. 5.2), and to local coupling (Sect. 5.3). Finally, we critically reflect on our study in Sect. 6, summarise our results in Sect. 7, and draw conclusions in Sect. 8.

\section{Background}

We distinguish three mechanisms by which evaporation affects precipitation (Fig. 1). These mechanisms are commonly investigated in separate studies. In this section we provide some (non-exhaustive) background for each of the three mechanisms (Sects. 2.1-2.3) and discuss at what spatial scales they act (Sect. 2.4).

\subsection{Moisture recycling}

In most studies dealing with moisture recycling the extent to which precipitation in some location depends on moisture recycling is linked directly to the recycling ratio $(R$, 
the fraction of recycled moisture in precipitation). Since the earliest studies on moisture recycling (Benton et al., 1950) several types of measures have been introduced to quantify moisture recycling. In the following we provide a basic overview of different recycling measures.

In many studies, including most of the earlier work, moisture recycling is quantified by the regional recycling ratio $\left(R_{\mathrm{r}}\right)$, which measures the contribution of evaporation from a particular region to precipitation inside the same region (e.g. Benton et al., 1950; Budyko, 1974; Lettau et al., 1979; Brubaker et al., 1993; Eltahir and Bras, 1994; Burde and Zangvil, 2001; Burde, 2006; Fitzmaurice, 2007). These studies are based on bulk recycling models that relate horizontal moisture influx and land-surface evaporation. For example, the bulk recycling equation applied by Brubaker et al. (1993) reads

$$
R_{r}=\frac{E_{\mathrm{r}}}{E_{\mathrm{r}}+2 \cdot F_{\mathrm{r}}}
$$

where $R_{\mathrm{r}}$ is the region's mean fraction of recycled moisture in precipitation, $F_{\mathrm{r}}$ is the region's horizontal moisture influx, and $E_{\mathrm{r}}$ is the region's land-surface evaporation. The individual bulk recycling models differ slightly from each other, with more recent models typically designed to relax the underlying assumptions. They are easily applicable to available data on moisture fluxes and land-surface evaporation, be it from models, observations, reanalyses, or other hybrid data. However, the bulk formulations have to employ simplifying assumptions that are hard to justify (see Fitzmaurice, 2007, for details). Also, the results depend strongly on the size and the shape of the considered region, because $E_{\mathrm{r}}$ scales with the region's area and $F_{\mathrm{r}}$ scales with its diameter perpendicular to the prevailing wind direction. Because of this scaleand shape-dependence the regional measure $R_{\mathrm{r}}$ is of limited use for the intercomparison of estimates between different regions (see van der Ent and Savenije, 2011, for details).

Trenberth (1999) overcomes this problem by introducing a local measure, the local recycling ratio. He modifies Brubaker's formulation by replacing the spatial integrals of $E$ and $F$ with their local values scaled up to some length scale, which gives globally comparable values. Dirmeyer and Brubaker (2007) estimate in principle the same quantity but with a more sophisticated method. Instead of applying a bulk formulation that entails the use temporal means, they compute a large number of back-trajectories to determine the source regions of precipitation, thereby accounting for the effect of transient fluxes. Another way to look at the local recycling ratio is to replace the (length-scale dependent) local recycling ratio by the length scale at which the local recycling ratio reaches a certain value. A natural choice for this value is $1-\frac{1}{e}$, which makes the resulting length-scale correspond to the distance atmospheric air travels until the integrated surface evaporation measures up to the atmospheric moisture content (van der Ent and Savenije, 2011).
An alternative non-local measure not suffering from scale issues is the continental recycling ratio $\left(R_{\mathrm{c}}\right)$, where the considered region is the global land-surface. In case of the continental recycling ratio "recycled moisture" equates to "moisture of continental origin" or "terrestrial moisture", and $R_{\mathrm{c}}$ equates to the fraction of continental moisture in total moisture. In principle bulk recycling models can be applied to the global land-surface, but the assumptions made in the model derivations are not appropriate given the size, shape, and heterogeneity of the continents. Also, with growing complexity of the considered region, one is interested in spatially resolved recycling ratios rather than one single mean value. Instead, continental recycling ratios can be computed numerically by tracing water that is tagged according to its origin. This approach is adopted by Numaguti (1999), Bosilovich et al. (2002), Yoshimura et al. (2004), and van der Ent et al. (2010). While Numaguti (1999) and Bosilovich et al. (2002) trace moisture 3-dimensionally within general circulation model (GCM) simulations, Yoshimura et al. (2004) and van der Ent et al. (2010) use reanalysis data to trace moisture 2-dimensionally.

Yoshimura et al. (2004) and van der Ent et al. (2010) apply the well-mixed assumption which reduces the problem to two spatial dimensions. This assumption implies that the atmosphere is vertically well-mixed with respect to moisture fractions of different origin, which is one of the simplifications also employed in most of the bulk recycling models (see Burde, 2006; Fitzmaurice, 2007, for details). The approach taken by Numaguti (1999) and Bosilovich et al. (2002) does not require the well-mixed assumption, because the vertical moisture exchange is resolved explicitly. Despite this difference the authors of the four studies cited above find similar continental recycling ratios. As expected, $R_{\mathrm{c}}$ increases from upwind to downwind continental regions, for example from west to east over North America and Eurasia (in particular in northern summer), and from northeast to southwest over Amazonia. $R_{\mathrm{c}}$ maxima are around $60 \%$ in the tropics (yearround), and even $80 \%$ in the eastern part of central Eurasia (during northern summer).

The continental recycling ratio $\left(R_{\mathrm{c}}\right)$ is the measure that we use in this case study to quantify moisture recycling (see below).

\subsection{Local coupling}

While moisture-recycling studies focus on the influence evaporation exerts on precipitation via the atmosphere's moisture budget, i.e. in a spatio-temporally integrative manner (see Fig. 1), another class of studies focusses on the influence evaporation exerts on precipitation via the atmosphere's thermal structure, which we refer to as local evaporationprecipitation coupling, or simply local coupling (following the nomenclature in Seneviratne et al., 2010). In contrast to moisture recycling, where increased evaporation can only 
lead to increased precipitation (positive coupling), local coupling can be both positive or negative.

General circulation models of the atmosphere provide a convenient way to investigate the local coupling with perturbation experiments (e.g. Rowntree and Bolton, 1983; Beljaars et al., 1996; Schär et al., 1999; Pal and Eltahir, 2001; Hohenegger et al., 2009). The perturbed variable in these studies is not evaporation directly but the initial soil wetness, and the mechanism is consistently referred to as soil moisture-precipitation coupling. The link between soil moisture and evaporation is strong as long as moisture availability rather than energy is the evaporation-limiting factor (see Seneviratne et al., 2010, for details). Most of these studies find a positive coupling between soil moisture and precipitation, i.e. more precipitation above wetter soils. Studying convective summer precipitation over Europe with a regional climate model, Schär et al. (1999) find that the low Bowen ratio of wet soils leads to the buildup of a comparatively shallow boundary layer with high values of moist entropy, which is a source of convective instability. Further, the level of free convection is lowered, which facilitates the release of convective instability. Also, despite increased cloud cover, Schär et al. (1999) find larger net radiation into wet soils, meaning that more total moist entropy gets into the boundary layer. Findell and Eltahir (2003a) initialise a one-dimensional boundary layer model with different vertical profiles based on earlymorning observations from Illinois in North America and find that, depending on the early-morning situation, the triggering of moist convection can be favoured above either wet soils or dry soils, or the triggering can be independent of the soil wetness, i.e. atmospherically controlled. Based on these results Findell and Eltahir (2003b) find that during northern summer the eastern half of the United States of America tends to show positive soil moisture-precipitation coupling, while large parts of the western half are atmospherically controlled. Only a small region in the arid southwest tends to show negative coupling.

Hohenegger et al. (2009) demonstrate that the strength and even the sign of the evaporation-precipitation coupling in atmospheric models can vary strongly with the representation of moist convection. For a situation with weak synoptic forcing in a domain around the Alps they find that two of the three investigated parameterisation schemes yield positive coupling, while negative coupling occurs with the third parameterisation scheme and when moist convection is represented explicitly through higher resolution. The different signs of the coupling relate to the presence of a stable layer sitting on top of the planetary boundary layer, which in the explicit case can be penetrated only by the more vigorous boundary-layer thermals occuring over dry soils. It remains unclear to which extent the results of Hohenegger et al. (2009) can be generalised, because they may be rather special for the synoptic situation and the mountainous terrain under investigation (C. Hohenegger, personal communication, 2011). On the other hand, there is also observational evidence that current atmospheric models do not well represent the local coupling (Dirmeyer et al., 2006).

The Global Land-Atmosphere Coupling Experiment (GLACE), to which a dozen climate-modelling groups contributed with global experiments, presents a different view on soil moisture-precipitation coupling (Koster et al., 2004). Instead of uniformly increasing or decreasing the soil wetness in a certain region, a set of model runs generated with freely developing soil wetness is compared to a set of runs generated with prescribed soil wetness. The (local) landatmosphere coupling strength is then measured by the degree to which the variability of precipitation decreases due to the (global) prescription of soil wetness. This measure of coupling strength is considerably different from the definition used in the sensitivity studies cited above. First, the measure does not contain the sign of the coupling. Second, the measure implies that regions without naturally occuring interannual variability of soil wetness are diagnosed to exhibit no land-atmosphere coupling, even if imposed changes in soil wetness (e.g. due to irrigation or other land-use changes) would affect local precipitation. The latter is one of the reasons why Koster et al. (2004) find significant local coupling only in the transition zones between arid and humid climates where soil wetness naturally varies from year to year. Besides these differences, Koster et al. (2004) agree with Hohenegger et al. (2009) on the point that there is considerable disagreement between models regarding the local coupling.

The uncertainty associated with the representation of local coupling in atmospheric models highlights the need to confront models with evidence from observations. However, observational long-term soil-moisture data with sufficiently high resolution are scarce (Seneviratne et al., 2010). Another serious disadvantage of observational studies compared to modelling studies is that causal relations are much harder to establish, in particular due to the persistence of precipitation on different timescales. For this very reason Salvucci et al. (2002) question the observational evidence Findell and Eltahir (1997) provide for positive soil moistureprecipitation coupling in Illinois during northern summer. However, in a more recent study Findell et al. (2011) provide new evidence for positive local coupling in large parts of North America using observationally strongly constrained reanalysis data.

Analysing satellite-derived soil-wetness data and aircraft measurements from the Sahel, Taylor et al. (2007) find for situations where soil wetness varies spatially that meso-scale circulations act to place moist convection preferably in the circulations' updrafts, which correspond to dry patches (see also Taylor et al., 2011). However, this finding can not be equated with a negative soil moisture-precipitation coupling. The latter would imply that (total) precipitation decreases in response to an imposed increase of soil wetness - a relation that does not follow from the negative spatial correlation. Finally, we leave the question open whether this kind of coupling, where meso-scale circulations are involved, should be 
classified as "local coupling", or rather as an effect associated with changes in the atmospheric circulation (compare Fig. 1).

According to current knowledge positive evaporationprecipitation coupling seems to be the rule rather than the exception (Seneviratne et al., 2010). However, understanding local coupling is an ongoing effort that is a central objective of the Global Land/Atmosphere System Study (see e.g. van den Hurk and Blyth, 2008).

\subsection{Circulation}

Besides moisture recycling and local coupling, land-surface evaporation alters climate also via its influence on the largescale atmospheric circulation (Fig. 1). The climatic response mediated through changes in the large-scale circulation is not restricted to the region of anomalous surface-evaporation itself (as in case of the local coupling) or to regions along the downwind trajectories (as in case of moisture recycling), but can occur principally anywhere. Remote effects conveyed through the large-scale circulation are also known as "teleconnections".

The most obvious link between surface evaporation and the large-scale circulation relates to the surface-pressure distribution. When heated by solar radiation, the oceans export most of the absorbed energy as latent heat to the atmosphere (low Bowen ratio), while at the land surface a larger fraction is exported as sensible heat (high Bowen ratio) and hence warms the atmosphere. This contrast, which is the stronger the drier the continents are, results in rising motion and low-level convergence associated with low surface pressure ("thermal lows") over the warmer continents and sinking motion and low-level divergence associated with high surface pressure over the cooler oceans. Due to geostrophy the surface-pressure distribution in turn results in cyclonic lowlevel circulations around the continents and anticyclonic lowlevel circulations around the ocean basins. Not surprisingly this effect is strongest on the Northern Hemisphere during northern summer, the low-level westerlies over the Indian subcontinent as part of the cyclonic circulation around Eurasia being a prominent example. Note that these circulations are superimposed by other features of the large-scale circulation like the extratropical westerlies.

Shukla and Mintz (1982) demonstrate with global climate model experiments for northern summer that most of the surface-pressure contrast between land and ocean and the associated circulations vanish when the land surface is kept wet, and that the contrast and the associated circulations are amplified when the land surface is kept dry with strong implications for the global distribution of precipitation. Saeed et al. (2009) show with a regional climate model that the present-day intensity of irrigation on the Indian subcontinent acts to attenuate the differential heating between land and ocean significantly, thereby weakening the monsoonal low-level westerlies over the region with far-reaching consequences. To give another example, Kleidon and Heimann (2000) compare global model experiments with different rooting depths in tropical South America and Africa. They find that enhanced land-surface evaporation fuels the release of latent heat in the Intertropical Convergence Zone (ITCZ). This in turn results in amplification of the Hadley circulation, with implications also for the subsiding branch in the subtropics and even beyond.

\subsection{Scale aspects}

In reality as well as in global climate models surfaceevaporation affects climate through all of these mechanisms (Fig. 1) simultaneously. However, in some cases a (modelled) response can be attributed quite clearly to one of the mechanisms. For example, Schär et al. (1999) carry out moisture-budget calculations and conclude from these that "the simulated sensitivity (of precipitation to soil-moisture anomalies) cannot be interpreted with the classical recycling mechanism". Seneviratne et al. (2010) put it this way: "The key for understanding soil moisture-precipitation interactions lies more in the impact of soil moisture anomalies on boundary-layer stability and precipitation formation than in the absolute moisture input resulting from modified evapotranspiration". In Schär et al. (1999) it is also clear that the response is not caused by changes in the large-scale circulation because the integration domain, Europe, is relatively small. As a consequence the velocity field is largely determined by the driving lateral boundary data, such that even the transit of individual low pressure systems across the domain is largely prescibed.

The larger integration domain in Saeed et al. (2009) allows for more flexibility of the velocity field in response to changes within the domain. However, the full response of the large-scale circulation can only be accounted for with global experiments, as in Shukla and Mintz (1982) and Kleidon and Heimann (2000). One may speculate whether a remake of the study of Schär et al. (1999) with a global model would reveal that changes in the large-scale circulation significantly modify the response from local coupling alone. However, it seems plausible that below some spatial scale of the perturbation the local coupling rather than the circulation dominates the response at least at the place of the perturbation.

Similarly, there should also be a spatial scale above which considerations of the atmospheric moisture budget, i.e. moisture recycling, become important. The results of Schär et al. (1999) suggest that this threshold seems to be larger than the spatial scale considered in local-coupling studies (typically $100-1000 \mathrm{~km}$ ). The length scale of moisture recycling (Sect. 2.1) might be a useful indicator. van der Ent and Savenije (2011) estimate that the length scale of moisture recycling can be as small as $\sim 1000 \mathrm{~km}$ in strongly evaporating regions with moderate horizontal moisture flux densities (large $E / F$, in July e.g. tropical Africa, southern Europe, and eastern North America), $\sim 2000-4000 \mathrm{~km}$ in regions with 
intermediate $E / F$ (in July e.g. central Europe, large parts of South America, and western North America), and larger than $5000 \mathrm{~km}$ in regions with low $E / F$ like deserts (see Fig. 8a in van der Ent and Savenije, 2011). Probably the scale at which moisture recycling becomes significant is already substantially below the length scale at which the integrated evaporation flux measures up to the atmospheric water content. In any case it seems that for evaporation perturbations imposed to regions larger than $\sim 1000 \mathrm{~km}$ cumulative changes in the atmospheric moisture content can not be neglected anymore.

The key for understanding the response of precipitation to an evaporation anomaly may lie in local coupling if the scale of the perturbation is sufficiently small, but at larger scales moisture recycling and the large-scale circulation come into play. With this study we approach the issue of scaledependence from the largest possible scale, namely the continental scale.

\section{Methods}

\subsection{Model experiments}

For our investigations we use the Earthsystem model of the Max Planck Institute for Meteorology (MPI-ESM), comprising the atmospheric general circulation model ECHAM6 (Roeckner et al., 2003), including the land-surface scheme JSBACH (Raddatz et al., 2007), at T63/L47 resolution $\left(1.875^{\circ} \times 1.875^{\circ}, 47\right.$ levels, $10 \mathrm{~min}$ time step $)$. We do not use the interactive MPI-ESM ocean component, but prescribe climatological sea-surface temperatures (SSTs) representing present-day conditions without interannual variability. Given the strong perturbation we apply (see below), the comparatively slight biases in the means of atmospheric quantities that are introduced through the use of climatological SSTs are tenable.

We run the model in two configurations. The reference experiment "REF" represents present-day conditions. In the second experiment "DRY" the continents are not allowed to exchange moisture with the atmosphere through evaporation (and, less importantly, condensation) but only through precipitation. Thereby the continents behave essentially as if they were kept completely dry. In reality a similar hydrological behaviour of the continents could in principle be provoked by transforming the continents into coarse-textured or rocky deserts with sufficiently steep slopes allowing for exhaustive runoff.

Since we focus on the direct effect of continental evaporation, or rather its absence, we prescribe continental albedo and roughness from climatologies in both experiments. This reduces the number and complexity of interactions and feedbacks that would otherwise add secondary alterations to the modelled differences in climate. The albedo and roughness climatologies stem from a 30-years model run in equilibrium (meaning that the transient phase before the model reaches a quasi-equilibrium is omitted) with dynamically modelled albedo and roughness that is otherwise identical to the REF experiment. The two equilibrium experiments REF and DRY span 30 years each (again without transient phase).

To account for the uncertainty associated with the parameterisation of moist convection, we run each of the two model experiments with two different convection schemes. One of these is the original Tiedtke mass-flux scheme. The scheme includes both deep and shallow convection. Single-parcel ascents are used to test whether convection is triggered. The cloud-base mass-flux is determined by a moistureconvergence closure (Tiedtke, 1989). The other convection scheme, which is the standard scheme of the MPI-ESM, is still based on the Tiedtke mass-flux scheme, but the moistureconvergence closure is replaced by a closure that is based on convective available potential energy (Nordeng, 1994; Roeckner et al., 2003). Accordingly, the entrainment rates are also handled differently.

\subsection{Moisture tracing}

To quantify moisture recycling we compute continental recycling ratios $\left(R_{\mathrm{c}}\right.$, see Sect. 2.1) from climate model data in the following way. We destinguish two types of atmospheric moisture: oceanic and recycled. While oceanic moisture stems from ocean evaporation, recycled moisture stems from continental evaporation. The continental recycling ratio is the fraction of continental moisture (i.e. continentally recycled moisture, hereafter recycled moisture) in total moisture.

$R_{\mathrm{c}}=\frac{M_{\mathrm{c}}}{M_{\mathrm{c}}+M_{\mathrm{o}}}$

where $M_{\mathrm{c}}$ is recycled moisture and $M_{\mathrm{o}}$ is oceanic moisture. In principle this measure is defined at every point in space and time in the atmosphere for infinitesimal volumes. We, however, apply the well-mixed assumption which implies that $R_{\mathrm{c}}$ is taken to be vertically constant. Accordingly, $M_{\mathrm{c}}$ and $M_{\mathrm{o}}$ are vertically integrated moisture densities. Ignoring temporarily that horizontal wind velocities generally vary with height, the problem reduces to two spatial dimensions. With these simplifications we can consider a Lagrangian atmospheric column travelling horizontally with the wind. The source and sink terms for $M_{\mathrm{c}}$ and $M_{\mathrm{o}}$ now read

$$
\begin{aligned}
& \frac{\mathrm{d} M_{\mathrm{c}}}{\mathrm{d} t}=E_{\mathrm{c}}-R_{\mathrm{c}} \cdot P \\
& \frac{\mathrm{d} M_{\mathrm{o}}}{\mathrm{d} t}=E_{\mathrm{o}}-\left(1-R_{\mathrm{c}}\right) \cdot P
\end{aligned}
$$

where $t$ is time, $P$ is precipitation from the air column, and $E_{\mathrm{c}}$ is evaporation into the air column from land, and $E_{\mathrm{o}}$ is evaporation into the air column from the ocean. Using Eqs. (2)-(4), substituting $M_{c}+M_{\mathrm{o}}$ by $W$ (precipitable water), and transforming into Eulerian formulation yields

$$
\frac{\partial R_{\mathrm{c}}}{\partial t}+u_{\mathrm{eff}} \frac{\partial R_{\mathrm{c}}}{\partial x}+v_{\mathrm{eff}} \frac{\partial R_{\mathrm{c}}}{\partial y}=\frac{E_{\mathrm{c}}}{W} \cdot\left(1-R_{\mathrm{c}}\right)-\frac{E_{\mathrm{o}}}{W} \cdot R_{\mathrm{c}}
$$


continental recycling ratio

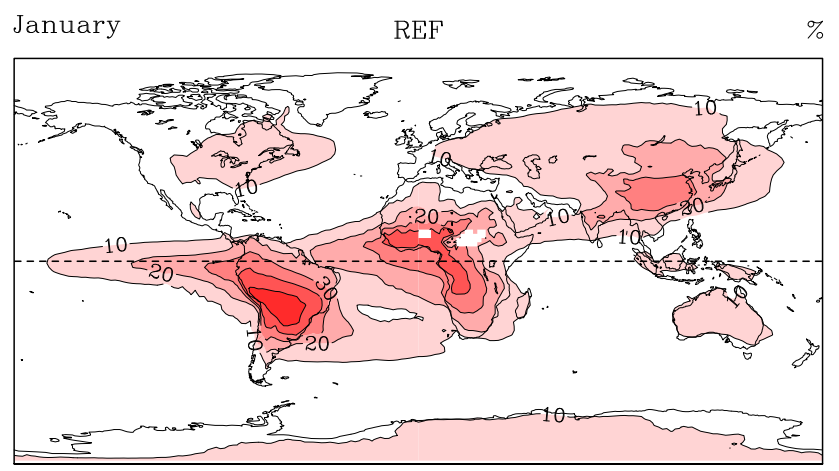

July REF $\quad \%$
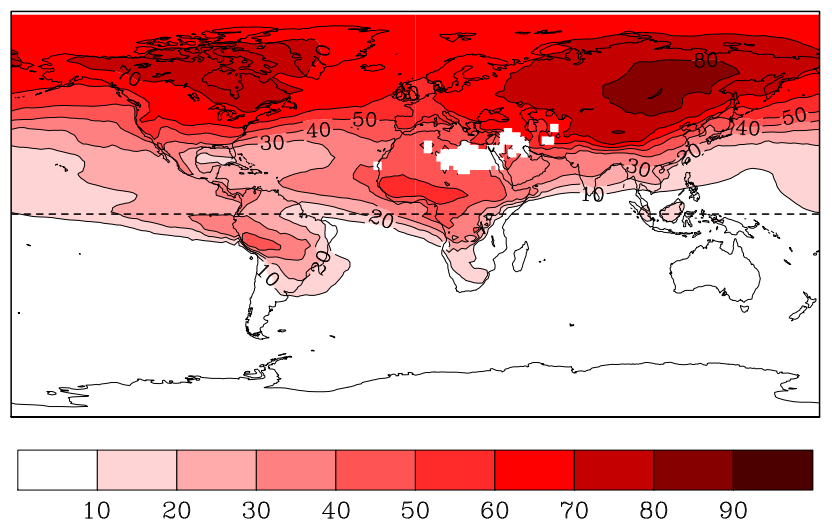

Fig. 2. Continental recycling ratio $R_{\mathrm{c}}$ (\% continental moisture in precipitation) in the REF experiment.

where $u_{\text {eff }}$ is the effective wind component along the zonal coordinate $x$, and $v_{\text {eff }}$ is the effective wind component along the meridional coordinate $y$. Since the air column can not be over land and over the ocean at the same time, only one of the right-hand-side terms can be nonzero at a time, depending on the location. The effective wind components in this 2dimensional formulation are vertical mean values weighted by the local water vapour partial pressure, such that

$$
\begin{aligned}
Q_{\mathrm{u}} & =u_{\mathrm{eff}} \cdot W=u_{\mathrm{eff}} \cdot\left(g^{-1} \cdot \int_{0}^{p_{0}} q(p) \mathrm{d} p\right) \\
& =g^{-1} \cdot \int_{0}^{p_{0}} u(p) \cdot q(p) \mathrm{d} p
\end{aligned}
$$

where $Q_{\mathrm{u}}$ is the zonal component of the vertically integrated horizontal moisture flux, $g$ is gravitational acceleration, $p$ is pressure, $p_{0}$ is surface pressure, and $q$ is specific moisture (all phases). Equation (6) analogously applies to the meridional component of the vertically integrated horizontal moisture flux, $Q_{\mathrm{v}}$. Equations (5) and (6) can also be derived from vertical integration of the full 3-dimensional equations (not shown). evaporation, moisture flux

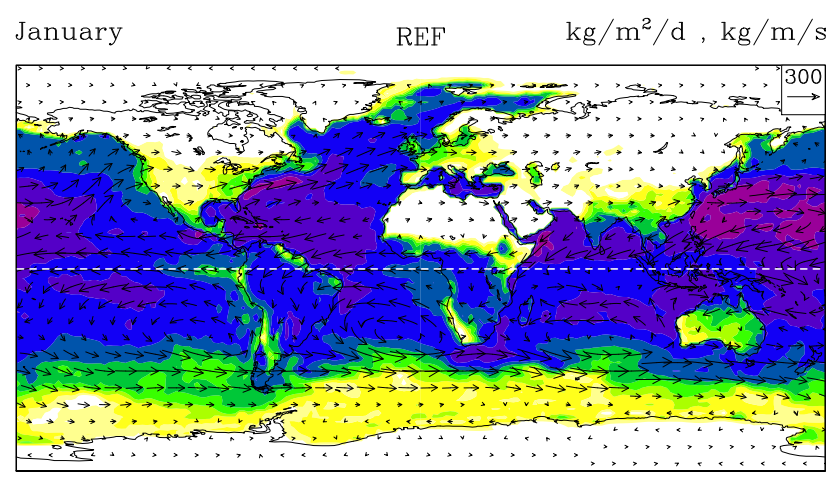

July REF $\quad \mathrm{kg} / \mathrm{m}^{2} / \mathrm{d}, \mathrm{kg} / \mathrm{m} / \mathrm{s}$
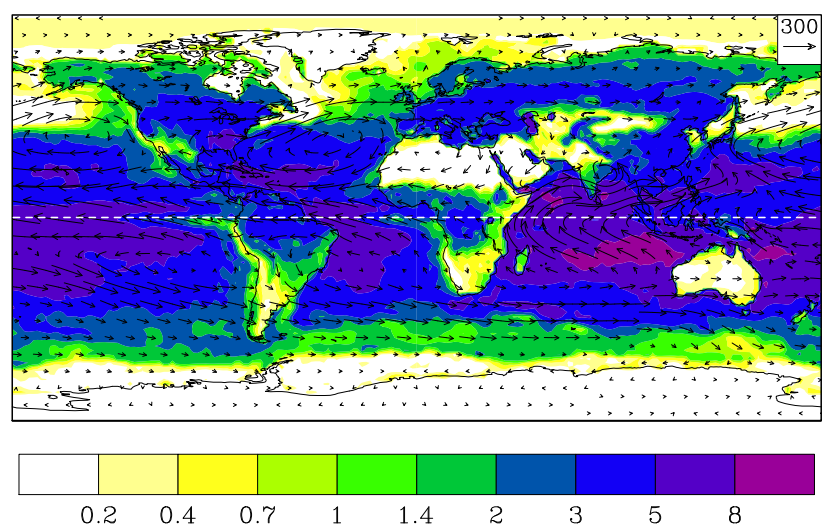

Fig. 3. Surface evaporation $E$ (colours, $\mathrm{kg} \mathrm{m}^{-2} \mathrm{~d}^{-1}$ ) and horizontal moisture flux density $Q$ (arrows, $\mathrm{kg} \mathrm{m}^{-1} \mathrm{~s}^{-1}$ ) in the REF experiment.

Equation (5) reveals that precipitation, although occuring in Eqs. (3) and (4), does not influence $R_{\mathrm{c}}$ directly. The reason is that, with the well-mixed assumption, precipitation removes recycled moisture and oceanic moisture from the atmospheric column in proportion to their respective abundance. Precipitation affects $R_{\mathrm{c}}$ only indirectly through its effect on $W$.

We discretise Eq. (5) with upwind differencing (e.g. Press et al., 2007) on the spatio-temporal grid of the model data $\left(1.875^{\circ} \times 1.875^{\circ}, 10 \mathrm{~min}\right.$ time step $)$ and run the algorithm over all model years of the REF experiment. Again we incorporate only the results from the last 30 years of equilibrium climate into our analysis. Since there is no continental moisture in the DRY experiment, there is no need to apply the tracing to it.

\section{Recycling in the reference experiment}

The distribution of the continental recycling ratio (Fig. 2) is determined by the rate of surface evaporation, the horizontal moisture flux density (Fig. 3), and the land-sea geometry. As a result the continental recycling ratio increases 
from continental upwind coasts to downwind coasts with respect to the prevailing winds. Steep $R_{\mathrm{c}}$-gradients occur where strong evaporation combines with moderate horizontal moisture-flux density (e.g. tropical Africa), or where the air flows perpendicular to a steep evaporation gradient (e.g. Sahel in January), or a combination thereof (e.g. China in July). Since $R_{\mathrm{c}}$ is bound between zero and one (as follows from Eq. 5) and, hence, saturates when approaching these bounds, the $R_{\mathrm{c}}$-gradient also depends on the value of $R_{\mathrm{c}}$ itself.

Please note that the monthly averaged continental recycling ratios shown in Fig. 2 are precipitation-weighted values rather than uniformly weighted time-averages (see the last paragraph in this section and Fig. S1 in the Supplement for a discussion of the consequences of this choice).

In the REF experiment continental moisture contributes up to $80 \%$ (on monthly average) to the atmosphere's total water content. This peak value is reached in central Asia, Siberia, and the north-eastern parts of North America in July. At this time of the year $R_{\mathrm{c}}$ exceeds $60 \%$ in the whole Arctic region, meaning that the main sources of moisture are the large land masses enclosing the pole. In January $R_{\mathrm{c}}$ in the northern extratropics hardly reaches $20 \%$ because of strongly reduced land-surface evaporation. In the southern extratropics $R_{\mathrm{c}}$ is low even during the Southern-Hemisphere summer (January) because of the absence of comparatively large land masses.

In the tropics $R_{\mathrm{c}}$ peaks at about $50 \%$ in the downwind regions of Africa and South America with weak seasonality. Despite strong land-surface evaporation continental moisture does not accumulate in the tropics as much as it does in the northern extratropics during summer, because air travelling between the tropical continents encounters large, strongly evaporating ocean basins. In consequence, air reaching South America or Africa contains almost no recycled moisture. This is different in the northern extratropics, where $R_{\mathrm{c}}$ is still relatively high after an ocean crossing. Additionally, horizontal moisture flux densities are usually higher in the tropics because the warmer atmosphere contains more moisture (Fig. 3, see also Fig. 5, top panel).

Comparing estimates averaged over the same period of time, our results agree well with the estimates published by Numaguti (1999), Bosilovich et al. (2002), Yoshimura et al. (2004), and van der Ent et al. (2010). (In the latter study the continental recycling ratio is termed "continental precipitation recycling ratio" and is different from the also discussed "continental evaporation recycling ratio".) The similarity of the estimates obtained with 2-dimensional tracing, which our study has in common with Yoshimura et al. (2004) and van der Ent et al. (2010), compared to the estimates obtained with 3-dimensional tracing (Numaguti, 1999; Bosilovich et al., 2002), suggests that the error introduced by the vertical integration is acceptably small for our large-scale considerations.

Regarding the comparability of the results there are two more technical differences to mention. First, Yoshimura et al. (2004) and van der Ent et al. (2010) do not trace moisture near the poles but treat moisture entering from the polar regions as oceanic moisture. In northern summer, when we obtain almost $70 \%$ continental moisture in the Arctic, Yoshimura et al. (2004) and van der Ent et al. (2010) obtain significantly lower values adjacent to the Arctic. Due to the prevailing zonal direction of the moisture transport, this seems to have minor influence on the continental recycling ratios below $\sim 70^{\circ}$ north. Second, in contrast to the other four studies including ours, Numaguti (1999) shows uniformly weighted time-averages instead of precipitationweigthed values. The resulting differences are small for monthly means, but not negligible for annual means because on the annual time scale continental recycling ratios and precipitation covary significantly (see Fig. S1 in the Supplement).

Please note that in all studies, including Bosilovich et al. (2002) and van der Ent et al. (2010) who show values only on the continents, continentally recycled moisture (i.e. moisture of continental origin) is also tracked in the atmosphere over the ocean. One can argue that moisture of continental origin that rains into the ocean should not be called continentally recycled. However, although we show values also over the ocean, we use this term to emphasise that our continental recycling ratio is the same quantity as the one discussed in van der Ent et al. (2010).

\section{Response to suppressed continental evaporation}

To keep this paper concise, in the following we focus on the results for July only, when continental evaporation and, hence, moisture recycling are most pronounced (compare Figs. 2 and 3). The main conclusions we draw from the analysis of the situation in July are consistent with the situation in January. We provide all corresponding figures for January in the Supplement.

The use of the original Tiedtke convection scheme in place of the standard scheme yields a significantly different precipitation distribution in some places, particularly in the tropics. However, the response to the suppression of continental evaporation is very similar with both schemes (see Fig. S2 in the Supplement), indicating that our results are to some extent robust to the choice of the convection scheme. Due to the similarity of the responses, in the following we discuss only the results obtained with the standard convection scheme.

We argue that, without local coupling and changes in the large-scale circulation, the hydrological response to the suppression of continental evaporation would closely resemble the pattern of continental recycling ratios in the REF experiment. Building on this argument we suggest that the significance of continental moisture recycling compared to other mechanisms can be judged by the similarity between the pattern of continental recycling ratios and the pattern of the hydrological response. In the following we thus first try to interpret the response to the suppression of continental 
evaporation from a moisture-recycling perspective by comparing these patterns (Sect. 5.1), and then analyse in how far changes of the atmospheric circulation (Sect. 5.2) and local coupling (Sect. 5.3) contribute to the response.

\subsection{The moisture-recycling perspective}

If moisture recycling were the dominant factor controlling the response to the suppression of continental evaporation, the response of precipitation (Fig. 4) and precipitable water (Fig. 5) would mirror the pattern of continental recycling ratios in the REF experiment (Fig. 2, bottom). To underline the moisture-recycling perspective, the difference plots of precipitation and precipitable water show relative differences with the red part of the colour scale kept identical to the colour scale of the continental recycling ratios.

For the moment ignoring the sign of the response, the changes in precipitation and precipitable water in July (Figs. 4 and 5) conform to the continental recycling ratios in two large-scale aspects (Table 1). First the response is stronger on the Northern Hemisphere $(\triangle P=-21 \%$, $\Delta W=-3 \%)$ than on the Southern Hemisphere $(\Delta P=-8 \%$, $\Delta W=-0.8 \%)$. This is in line with the continental recycling ratio $\left(\mathrm{NH}: R_{\mathrm{c}}=31 \%, \mathrm{SH}: R_{\mathrm{c}}=3 \%\right)$. However, this tendency would be expected also for effects due to local coupling or effects due to changes in the large-scale circulation, because the perturbation is much stronger on the Northern Hemisphere (see continental evaporation rates in Fig. 3, bottom panel). Second the response is much stronger over the continents $(\Delta P=-54 \%, \Delta W=-7 \%)$ than over the ocean $(\Delta P=-7 \%, \Delta W=-0.4 \%)$. This is also in line with the response one would expect if moisture recycling were the dominant mechanism (land: $R_{\mathrm{c}}=50 \%$, ocean: $R_{\mathrm{c}}=14 \%$ ). However, a stronger response on the continents compared to the ocean would also be expected if local coupling were the dominant factor. Regarding effects from the large-scale circulation one expects a response not only over the continents but also over the ocean, although it is less clear to what extent changes in the circulation should affect the continents more than the ocean (compare Sect. 2.3). In summary, these two large-scale aspects (the stronger response (I) in the Northern Hemisphere and (II) over the continents) conform to the moisture-recycling perspective but, because they could also be due to non-recycling mechanisms, they do not suffice to attribute the response to moisture recycling.

Now also accounting for the sign of the response, the probably strongest evidence from large-scale aspects supporting that moisture recycling contributes at least to some extent to the response is the globally prevailing decrease of precipitable water, in particular over the continents (Table 1). The much stronger decrease of precipitation is also in line with the continental recycling ratios, but in contrast to precipitable water a strong decrease of precipitation over the continents could also be due to positive local coupling.
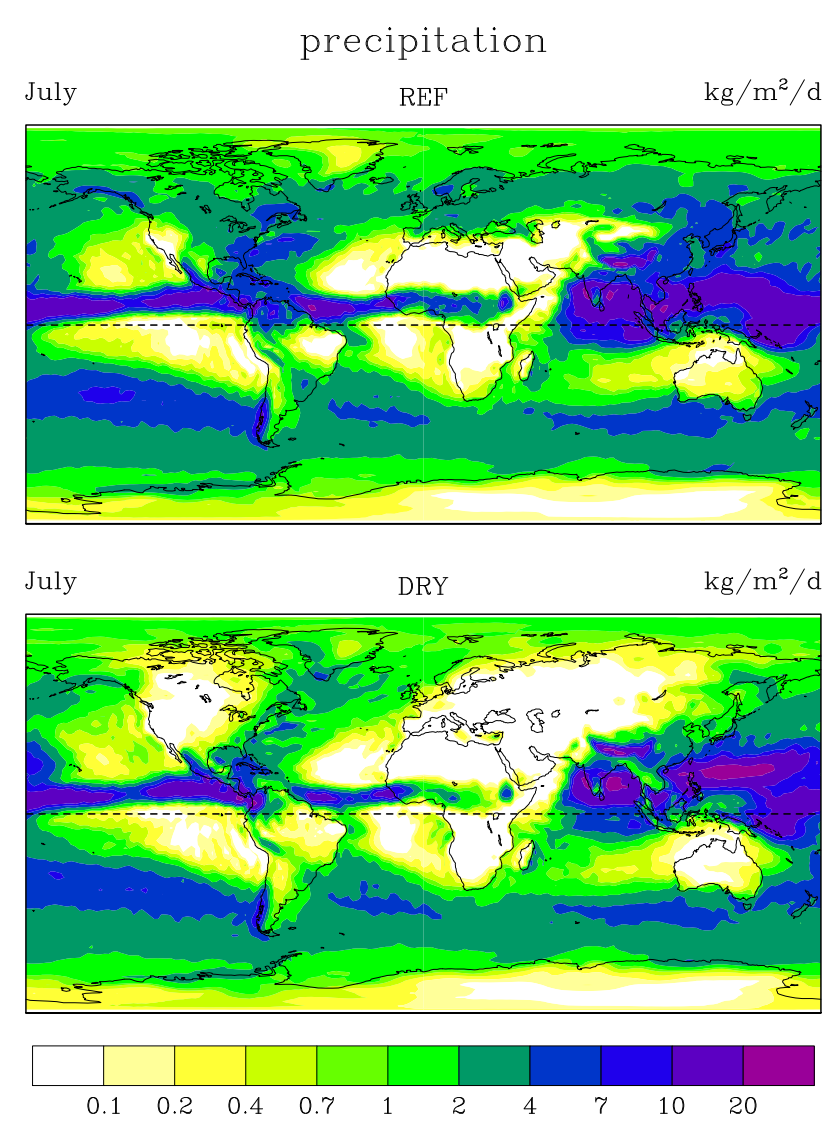

July DRY-REF \% of REF
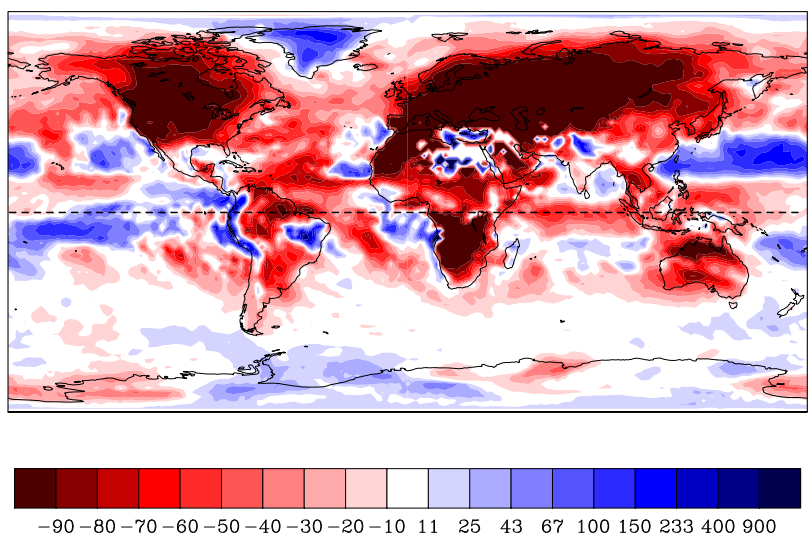

Fig. 4. Precipitation $\left(\mathrm{kg} \mathrm{m}^{-2} \mathrm{~d}^{-1}\right)$ in July in the REF experiment (top panel), in the DRY experiment (middle panel), and the difference between the two (bottom panel, \%). Note that the red part of the colour scale of the difference plot is kept identical to the one used in Fig. 2 to allow for direct comparison. The values of the blue part of the colour scale of the difference plot equate to $(10 \%$, $20 \%, \ldots, 90 \%)$ in relation to the DRY experiment. See Fig. S3 in the Supplement for January. 


\section{precipitable water}
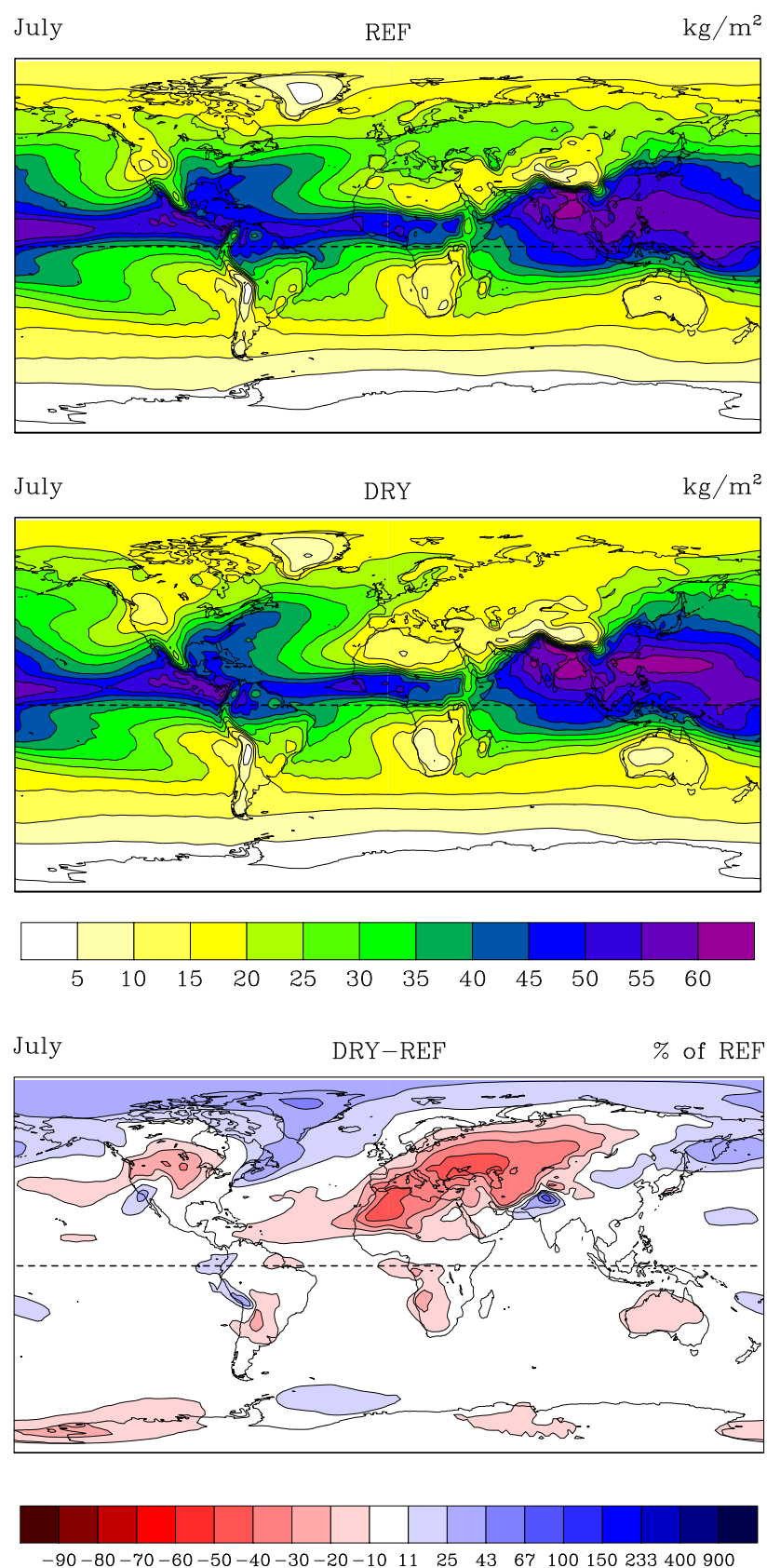

Fig. 5. Precipitable water $\left(\mathrm{kg} \mathrm{m}^{-2}\right.$, vapour + liquid + ice $)$ in July in the REF experiment (top panel), in the DRY experiment (middle panel), and the difference between the two (bottom panel, \%). Note that the colour scale of the difference plot is kept identical to the ones used in Figs. 2 and 4, bottom, to allow for direct comparison. The values of the blue part of the colour scale of the difference plot equate to $(10 \%, 20 \%, \ldots, 90 \%)$ in relation to the DRY experiment. See Fig. S4 in the Supplement for January.
A clear indication that other mechanisms than moisture recycling contribute substantially to the signal is the occurrence of increased precipitation and increased precipitable water in many regions (Figs. 4 and 5). The atmosphere in the Arctic carries about $30 \%$ more water in the DRY experiment, although almost $70 \%$ of the atmospheric water in the REF experiment stem from continental evaporation. Greenland receives $40 \%$ more precipitation in the DRY experiment. Other regions with increased precipitation include the Himalayas, eastern Brazil, the Andes, and the edges of the Pacific ITCZ. While moisture recycling can not explain any increase in precipitation or precipitable water in response to decreased evaporation, negative local coupling is a possible explanation for a precipitation increase only over land. The latter might be the case in eastern Brazil, where evaporation rates in the REF experiment are high, but negative local coupling as an explanation is implausible in Greenland, where (I) evaporation rates from the icy land-surface are low already in the REF experiment and (II) precipitable water is simultaneously increased in the whole region including the upwind located eastern coast of North America. It therefore seems that large parts of the response are not attributable to moisture recycling, but rather to differences in the large-scale circulation (see Sect. 5.2 for details).

Even without differences in the large-scale circulation it seems implausible that moisture recycling can "act" across an ocean basin as large as for example the Atlantic. First, in contrast to land, the ocean is an inexhaustible water reservoir for atmospheric considerations. Second the boundary layer, which contains most of the atmospheric moisture, is mostly well-mixed. This suggests that the hydrological state of the atmosphere has a short memory over the ocean, meaning that the moisture content returns to a quasi-equilibrium faster than it takes the air to cross a sufficiently large ocean basin. This implies that, for example, Eurasia is not affected by North America's evaporation and vice versa, at least not through moisture recycling - despite the substantial fraction of moisture they receive from each other as continental recycling ratios reveal (Fig. 2). Over land the situation is different: Since evaporation is constrained by moisture availability, an atmospheric dry-anomaly can persist and intensify. These considerations conform to the finding that the atmosphere over the ocean is not systematically drier in response to the suppression of continental evaporation (Fig. 5). To take into account that the continental recycling ratio of an air mass is irrelevant for its hydrological state after having crossed a large ocean basin, in the following we only consider intra-continental gradients of the continental recycling ratio when trying to attribute aspects of the hydrological response to moisture recycling. Note that the consideration of recycled (continental) moisture over the ocean is not specific to our study because in all earlier studies estimating continental recycling ratios the recycled moisture is tracked also over the ocean (compare Sect. 4, last paragraph). 
Table 1. Areal mean (July) continental recycling ratio $\left(R_{\mathrm{C}}\right)$, evaporation $(E)$, precipitation $(P)$, and precipitable water $(W)$ in the REF experiment, the response of $P$ and $W$ to the suppression of land-evaporation (DRY-REF), and $\Delta \mathrm{P}$ in relation to the imposed evaporation decrease ( $\triangle E=E_{\mathrm{REF}}$, valid for land only).

\begin{tabular}{|c|c|c|c|c|c|c|c|}
\hline Region & $\begin{array}{l}\text { Location } \\
{ }^{\circ} \mathrm{N} /{ }^{\circ} \mathrm{E}\end{array}$ & $\begin{array}{r}R_{\mathrm{c}} \\
\%\end{array}$ & $\begin{array}{l}E_{\mathrm{REF}} \\
\mathrm{kg} \mathrm{m}^{-2} \mathrm{~d}^{-1}\end{array}$ & $\begin{array}{c}P_{\mathrm{REF}} \\
\mathrm{kg} \mathrm{m}^{-2} \mathrm{~d}^{-1}\end{array}$ & $\begin{array}{r}\Delta P \\
\% \text { of } \mathrm{REF}\end{array}$ & $\begin{array}{r}W_{\mathrm{REF}} \\
\mathrm{kg} \mathrm{m}^{-2}\end{array}$ & $\begin{array}{r}\Delta W \\
\% \text { of } \mathrm{REF}\end{array}$ \\
\hline Europe* & $37 . .71 /-10 . .59$ & 66 & 3.0 & 2.2 & -95 & 25 & -29 \\
\hline Africa* & $-34 . .37 /-18 . .59$ & 52 & 1.0 & 0.9 & -66 & 27 & -12 \\
\hline Northern Asia* & $37 . .76 / 59 . .179$ & 77 & 2.4 & 2.5 & -79 & 23 & -5 \\
\hline Southern Asia* & $7 . .37 / 59 . .140$ & 41 & 2.4 & 5.4 & -29 & 39 & -3 \\
\hline Oceania* & $-47 . .7 / 97 . .177$ & 8 & 1.0 & 1.1 & -46 & 21 & -7 \\
\hline North America* (excl. Gr.) & $11 . .78 /-166 . .-53$ & 59 & 2.9 & 2.8 & -69 & 25 & -3 \\
\hline Greenland* & $60 . .84 /-70 . .-14$ & 69 & 0.14 & 1.2 & +40 & 8 & +34 \\
\hline South America* & $-54 . .11 /-82 . .-35$ & 23 & 2.4 & 2.2 & -38 & 30 & -4 \\
\hline Global land & & 50 & 1.8 & 2.1 & -54 & 24 & -7 \\
\hline Global ocean & & 14 & 3.7 & 3.6 & -7 & 29 & -0.4 \\
\hline Northern Hemisphere & & 31 & 2.8 & 3.9 & -21 & 35 & -3 \\
\hline Southern Hemisphere & & 3 & 3.5 & 2.4 & -8 & 20 & -0.8 \\
\hline Global land \& ocean & & 20 & 3.2 & 3.2 & -16 & 28 & -2 \\
\hline
\end{tabular}

* land only

Continental recycling ratios increase from continental upwind regions to downwind regions (Fig. 2). This conforms to the expectation that dry-anomalies should intensify along atmospheric trajectories over the continents in response to suppressed land-evaporation. Hence, from the moisturerecycling perspective, changes in precipitable water and, consequently, precipitation are expected to be smaller in upwind regions and progressively larger (negative) towards downwind regions (compare Fig. 3). But our experiments show a different response. Over Eurasia the hydrological response is opposite to what would be expected from the recycling ratios: In the upwind (western) parts of Eurasia the atmosphere carries up to $40 \%$ less moisture in the DRY experiment compared to the REF experiment. The drying declines in eastward direction until at the eastern coast of Asia the atmosphere carries even $20 \%$ more moisture in the DRY experiment (Fig. 5). The precipitation response is similar, though stronger in magnitude: The largest part of western Eurasia receives less than $10 \%$ of the precipitation in the REF experiment. Only in the easternmost part of extratropical Eurasia the precipitation decrease declines (Fig. 4). These tendencies recur very similarly in North America. Apparently the extratropical response is dominated by non-recycling mechanisms.

In the Tropics the hydrological response is strongly influenced by non-recycling mechanisms as well. In tropical Africa the continental recycling ratio peaks north of the equator, in particular in tropical West Africa (Fig. 2, bottom panel). In contrast, precipitable water is almost unchanged in tropical West Africa, but considerably decreased south of the equator along Africa's western coast (Fig. 5). The response of precipitation approximately resembles the response of precipitable water (Fig. 4). However, focussing only on those parts of Africa located south of the equator with prevailing easterlies in July, the response to some extent conforms to the moisture-recycling perspective: Continental recycling ratios increase from approximately $0 \%$ at the upwind (eastern) coast to $10-40 \%$ at the downwind (western) coast, while precipitable water and precipitation are more or less unchanged at the upwind coast, but decreased by $20 \%$ and almost $100 \%$, respectively, at the downwind coast. Note, however, that the absolute amounts of precipitation and precipitable water in this region are already low in the REF experiment, with strong meridional gradients (Figs. 4 and 5, upper panels).

Similar to Africa, in tropical South America we find on the one hand that mechanisms other than moisture recycling substantially contribute to the signal, while on the other hand the response to some extent conforms to the moisture-recycling perspective. The increase of precipitable water and precipitation along the downwind located tropical part of the Andes (Figs. 4 and 5) stands in contrast with the coinciding maximum of the continental recycling ratio (Fig. 2, bottom panel). At the upwind located eastern coast neither the precipitation increase south of the equator, nor the decrease of precipitable water as well as precipitation from the equator northward can be explained by moisture recycling. However, the drying around the Tropic of Capricorn seems to be at least partly attributable to moisture recycling. When the air is advected from the Atlantic to eastern Brazil it is still as moist in the DRY experiment as in the REF experiment, but along the south-bending trajectory (compare Fig. 3, bottom panel) a dry-anomaly intensifies until around Paraguay the atmosphere is $20 \%$ drier in the DRY experiment, accompanied 
by $70 \%$ less precipitation. Compared to southern tropical Africa the absolute amounts of precipitable water and precipitation are considerably larger and, hence, the response more meaningful.

\subsection{Response of the atmospheric circulation}

As elaborated in the last section the response of precipitable water and precipitation seems to be largely dominated by other mechanisms than moisture recycling (compare Fig. 1). In this section we show how the large-scale circulation reacts to the suppression of continental evaporation (compare also Sect. 2.3).

Due to the absence of latent cooling at the land surface, the continents are substantially warmer without continental evaporation (Fig. 6, top panel). Not surprisingly the spatial distribution of the warming conforms rather closely to the evaporation rate in the REF experiment (Fig. 3, bottom panel), though the response is amplified in the northern extratropics in summer because of reduced cloud cover in the DRY experiment (not shown). While tropical Africa and tropical South America are about $7 \mathrm{~K}$ warmer in the DRY experiment, the continental northern midlatitudes, which exhibit comparable evaporation rates in summer in the REF experiment, are 10-15 K warmer in the DRY experiment. Deviations of the warming from the evaporation rates in the REF experiment are also due to the fact that the surface temperatures are not only locally determined, but also by advection. For example the record warming (more than $15 \mathrm{~K}$ ) around Lake Baikal, located in the downwind parts of Eurasia, is supported by the intensification of heat-anomalies along the air's path over the largest of all continents.

The direction of the response of the large-scale circulation is basically in agreement with Shukla and Mintz (1982), although Shukla and Mintz (1982)'s wet-soil case is much wetter than our REF experiment. As in Shukla and Mintz (1982) the warming of the continents (Fig. 6, top panel) is accompanied by a decrease of surface pressure over the continents and a compensating increase of surface pressure over the ocean basins (Fig. 6, bottom panel). In particular the summerly heat lows over Eurasia and North America and the corresponding highs over the North Atlantic and the North Pacific are strongly enhanced, such that the pressure difference between the ocean basins and the continents $(15-25 \mathrm{hPa}$ in the REF experiment) almost doubles. In consequence the anticyclonic low-level circulations over the North Atlantic and the North Pacific as well as the cyclonic low-level circulations over Eurasia (together with northern Africa) and North America are strongly amplified (Fig. 7, arrows). The associated amplification of low-level convergence (and highlevel divergence) over the continents, measured by the mean vertical velocity at $500 \mathrm{hPa}$, is inhomogeneously distributed (Fig. 7).

Owing to the modified surface-pressure field the midlatitude westerlies over Eurasia and North America are
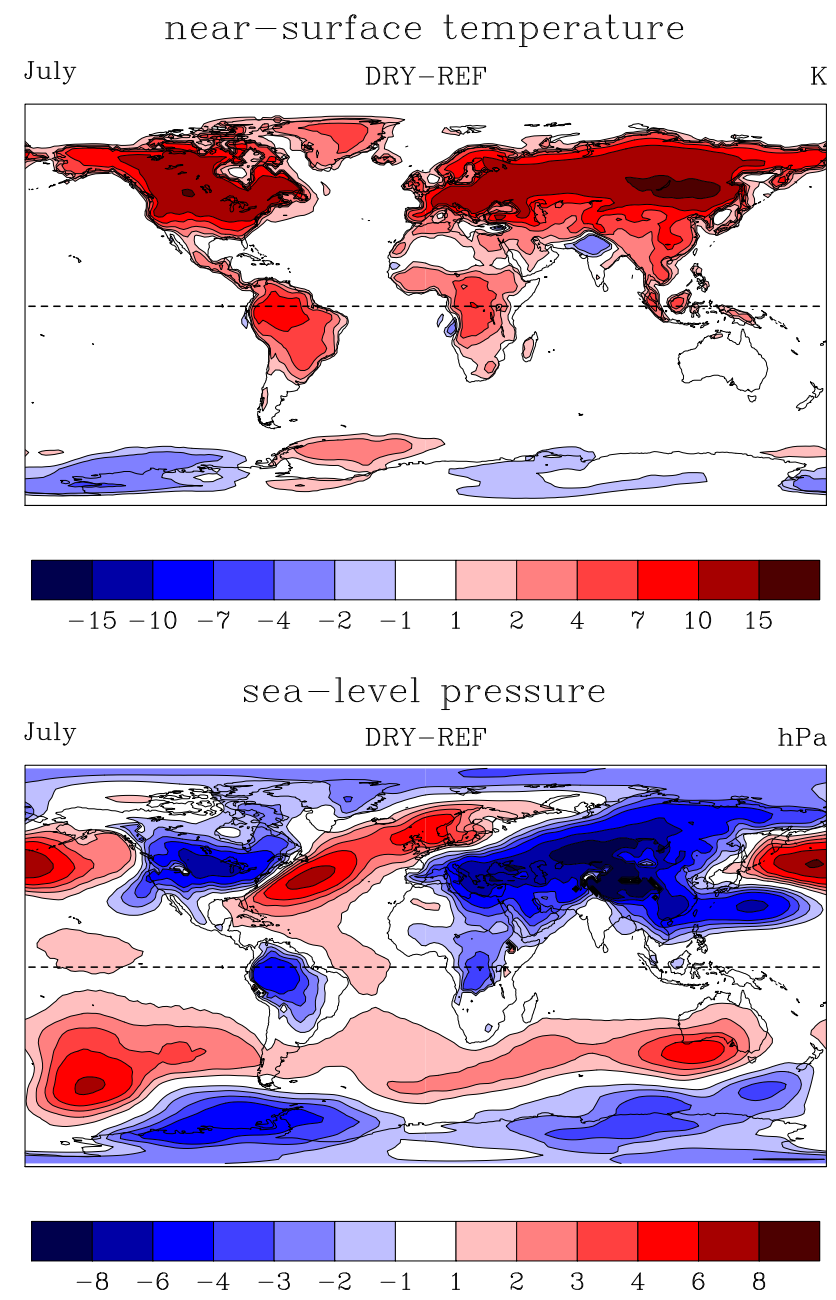

Fig. 6. Top panel: Difference in near-surface $(2 \mathrm{~m})$ temperature in July (K, DRY-REF). Bottom: Difference in pressure reduced to sea-level in July (hPa, DRY-REF). See Fig. S5 in the Supplement for January.

considerably weaker in the DRY experiment (Fig. 7). This results in more continental and, hence, drier conditions in particular in the western parts of the continents (Figs. 5 and 4). Precipitable water is most affected in a large region spanning from the western coast of northern Africa over the Mediterranean to the Caspian Sea because the westerlies over Europe are not only weaker, but partly even turn into northerlies, such that drier air masses from the north are advected into the region.

The strengthening of the cyclonical low-level circulation around Eurasia and northern Africa is also apparent in its southern branch, which includes the monsoonal low-level westerlies over the Indian subcontinent (Fig. 7). In consequence more moisture is advected from the Arabian Sea and precipitates when encountering the high mountain ranges of the Himalayas (Fig. 4). As a side remark, the strengthening of the westerlies over the Indian subcontinent also explains 


\section{$\Omega$ at $500 \mathrm{PPa}$, lower-atm. massflux}
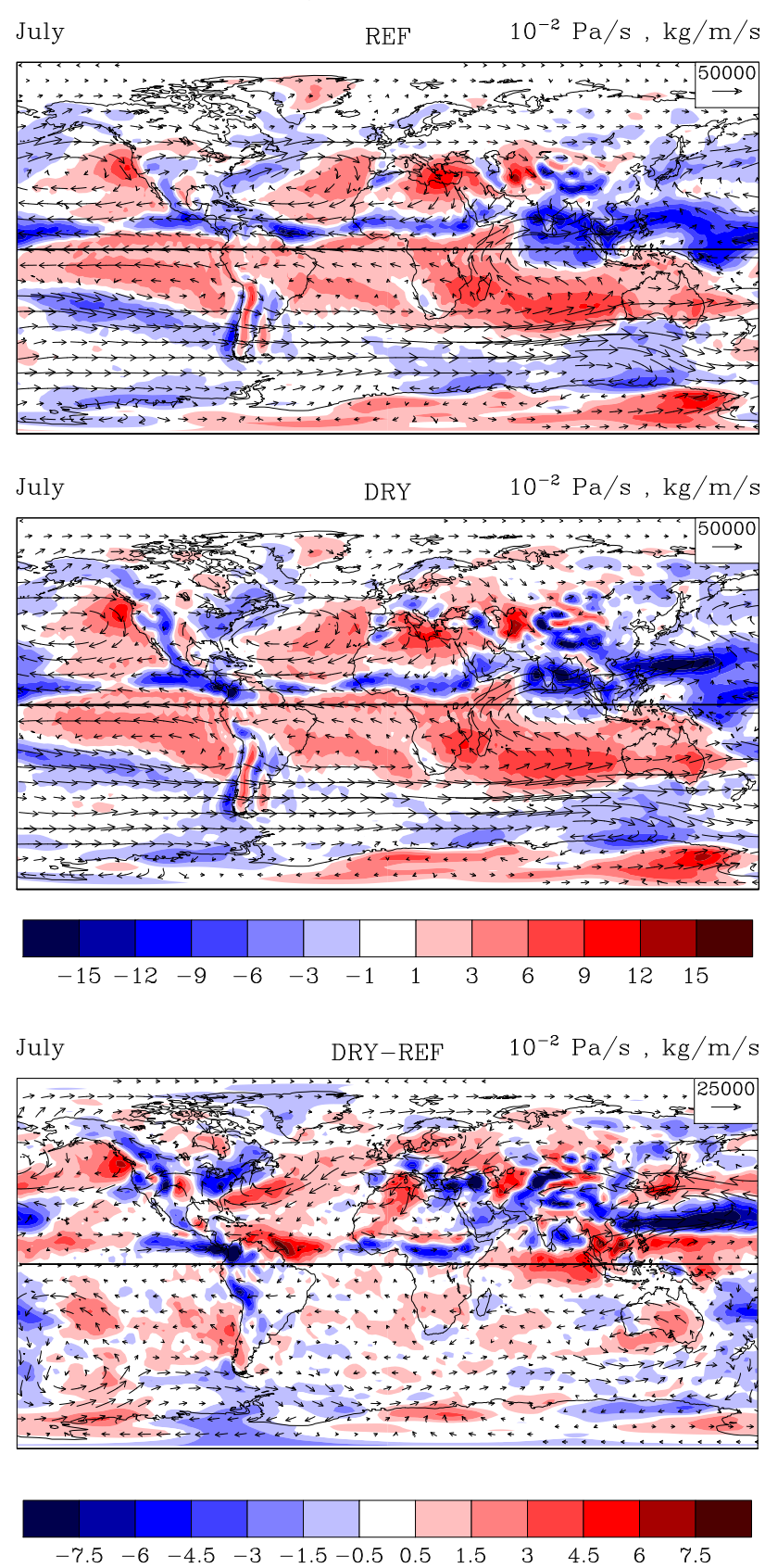

Fig. 7. Vertical velocity $(\Omega)$ at $500 \mathrm{hPa}$ (colours, $\mathrm{Pa} \mathrm{s}^{-1}$ ) and horizontal total mass flux in the lowest 13 model levels (arrows, $\mathrm{kg} \mathrm{m}^{-1} \mathrm{~s}^{-1}$ ) in July in the REF experiment (top panel), in the DRY experiment (middle panel), and the difference between the two (bottom panel). The lowest 13 model levels correspond approximately to the lower half of the atmosphere. Hence, the vertical velocity at $500 \mathrm{hPa}$ approximately corresponds to the divergence of the shown mass flux. Note that the scale for both $\Omega$ and the mass flux are changed by a factor 2 in the bottom panel to make the differences better visible. See Fig. S6 in the Supplement for January. the salient cooling in northern India and Pakistan (Fig. 6, top panel).

The differences in surface pressure (Fig. 6, bottom panel) result in stronger low-level southwesterlies along the eastern coast of North America and the eastern coast of Eurasia north of Japan (Fig. 7) in the DRY experiment. Consequently, more moisture is transported into the Arctic, where precipitable water is increased by about $30 \%$ and precipitation is also considerably enhanced, particularly in Greenland.

Because of the absence of the Coriolis force at the equator, the decreased surface pressure in tropical South America and tropical Africa (Fig. 6, bottom panel) does not cause continental-scale changes of low-level vorticity (Fig. 7). But the low-level convergence patterns (in particular the ITCZ, measured by the vertical velocity at $500 \mathrm{hPa}$, Fig. 7) are strongly altered in response to the suppression of continental evaporation. While in the REF experiment in July the ITCZ is similarly strong to the west and to the east of Central America, the western part over the Pacific is much stronger than the eastern part over the Atlantic in the DRY experiment, associated with increased and decreased precipitation, respectively (Fig. 4). In Africa the ITCZ is shifted southward in the DRY experiment. While most of tropical Africa experiences much drier conditions, the precipitation rates around $5^{\circ} \mathrm{N}$, now located within the ITCZ, are not as much decreased as to the north and to the south. Over the tropical warm pool areas in the Indic and the western Pacific the ITCZ is considerably shifted to the north, while over the central Pacific the double-ITCZ is more pronounced in the DRY experiment than in the REF experiment. Again, these changes are reflected in the precipitation rates (Fig. 4). The strong modifications of the low-level convergence patterns and precipitation over the ocean are particularly remarkable given that the two experiments are driven with identical SSTs.

\subsection{Effects from local coupling}

From the comparison of continental recycling ratios with the actual hydrological response (Sect. 5.1) and the elucidation of changes in the large-scale circulation (Sect. 5.2) it becomes apparent that effects associated with the large-scale circulation rather than moisture recycling dominate the overall response. However, it still seems astonishing that (I) the precipitation response is so extreme, whereby the most extreme decrease of almost $100 \%$ is comparatively sharply delimited to the continents, and (II) that, apart from some tropical exceptions, the upwind to downwind drying-gradients one would expect from moisture-budget considerations are completely absent. Admittedly the latter is to a large part due to changes in the large-scale circulation, but one has to note that for example the westerlies over Eurasia and North America, although significantly attenuated, are still westerlies in the DRY experiment. These arguments suggest that another factor contributes to the overall response, namely (positive) local evaporation-precipitation coupling (compare Fig. 1). 

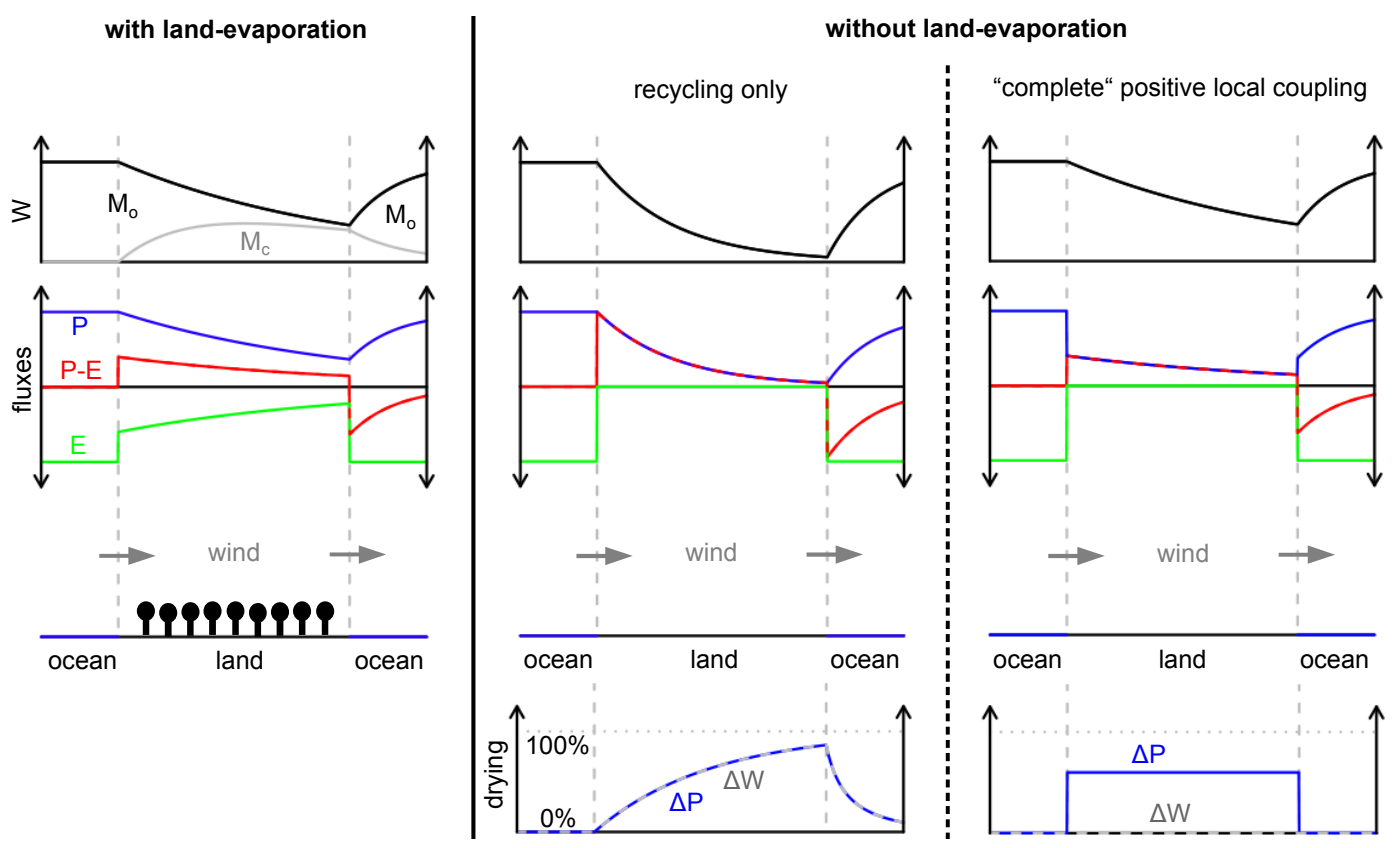

Fig. 8. Illustration of two principally possible idealised responses to the suppression of land-evaporation as 1-D-transects through a continent. Left panel: reference situation with continental evaporation. Middle panel: response to the suppression of continental evaporation dominated by moisture-recycling. Right: response to the suppression of continental evaporation in a special case: The decrease in precipitation completely compensates for the missing evaporation, such that $P-E$ is unaffected. $W=$ precipitable water, $M_{\mathrm{O}}=$ oceanic moisture, $M_{\mathrm{c}}=$ continentally recycled moisture, $P=$ precipitation, $E=$ evaporation. The graphs at the bottom show the relative reduction $\left(\frac{\mathrm{REF}-\mathrm{DRY}}{\mathrm{REF}}\right)$ of $P$ (blue, solid) and $W$ (grey, dashed). Units are arbitrary.

The comparison of local vertical profiles of the thermal structure of the atmosphere between our two experiments is not as instructive as in the typical local-coupling studies (compare Sect. 2.2) because the advected profiles at any location are already different between the experiments due to the strong response of the large-scale circulation. However, it is reasonable that the substantially drier and warmer continental surfaces (Fig. 6, top panel) strongly influence the local generation of precipitation.

In eastern Brazil, where neither moisture recycling nor changes in the large-scale circulation seem to be responsible for the precipitation increase (Fig. 4), the response may be caused by negative local coupling. Otherwise the strong precipitation decrease over most continental regions correlates to the evaporation rates in the REF experiment (Fig. 3, bottom panel), which points at positive local coupling. Schär et al. (1999) find with regional simulations for summerly Europe that the decrease of precipitation amounts to approximately half of the imposed decrease of evaporation (see also next section). This makes it also quantitatively plausible that a significant fraction of the precipitation decrease we find in response to the suppression of continental evaporation may actually be attributable to positive local coupling, although this is hard to prove from our results.

In principle it seems possible that under certain circumstances the response of precipitation due to positive local coupling completely compensates for changes in evaporation, such that the net water loss from the atmosphere to the land (precipitation minus evaporation, $P-E$ ) remains unaltered despite the suppression of evaporation. This possibility suggests a simplistic but yet instructive picture that is illustrated in Fig. 8.

The figure contrasts two possible idealised responses to the suppression of land-evaporation, one with moisture recycling dominating the response (middle panel), and one with non-recycling mechanisms acting to cancel out the effect from moisture recycling (right panel). The figure shows profiles of precipitable water and surface fluxes as 1-D-transects through an idealised continent along the prevailing wind direction, with oceans situated upwind and downwind. Before landfall the air is in a quasi-equilibrium humidity state over the ocean, meaning that precipitation and evaporation are in balance $(P-E=0)$. In the reference situation (Fig. 8, left panel), the evaporative fraction over the continent is assumed to be constant at $60 \%$, meaning that $40 \%$ of the precipitation are removed from the system as runoff. With precipitation assumed to be a function of precipitable water $(W)$ only, here exemplarily as $P \propto W$ (compare Savenije, 1995), precipitable water and the surface fluxes decrease continuously (exponentially) from the upwind coast to the downwind coast. In parallel the continental recycling ratio $\left(M_{\mathrm{c}} / W\right)$ increases. When the air leaves the continent it returns to 
its initial equilibrium, with the ocean providing the moisture needed to remove the deficit $(P-E<0)$.

Like in the reference situation, in the moisture-recycling case (Fig. 8, middle panel) precipitation is assumed to be a function of precipitable water only $(P \propto W)$ and, hence, evolves continously with precipitable water. Without continental evaporation the progressive atmospheric moisture loss is stronger than in the reference situation. The relative reduction of both precipitable water and precipitation compared to the reference situation (bottom graph) increases from upwind to downwind, conforming to the increase of the continental recycling ratio in the reference situation.

Instead we now assume the special case that, due to strong positive local coupling, the decrease in precipitation results in unchanged $P-E$ (Fig. 8, right panel). In consequence, precipitable water evolves as in the reference situation, and the relative precipitation decrease is $60 \%$ on the whole continent - the upwind to downwind drying-gradient vanishes (bottom graph). In other words, the upwind response due to "complete" positive local coupling annihilates the effect one would expect from moisture recycling.

Before coming to the major conclusion we draw from this simplistic picture, we analyse in how far the response of precipitation compensates for the missing moisture input by evaporation in our model experiments. Figure 9 (bottom panel) reveals that in July $P-E$ over land tends to increase in response to the suppression of continental evaporation. This means that, in contrast to the simplistic case of "complete" positive local coupling illustrated in Fig. 8, the response of precipitation does not completely compensate for the missing evaporation in most continental regions.

Relating the local response of precipitation to the local land-surface evaporation in the REF experiment (Fig. 10) however shows that in large parts of the continents the decrease of precipitation compensates for a substantial fraction of the missing evaporation. Closer inspection of the patterns in Figs. 9 and 10 further reveals that regions where the response of precipitation compensates for much less than $100 \%$ of the missing evaporation are almost exclusively located where in the REF experiment the land is a source of moisture in July. Such places include the tropical wet-dry climates that have their dry season in July when the ITCZ is located further to the north, but also the mid-latitude summerdry climates of Eurasia and North America. Where the land is a moisture source in the REF experiment (a situation that is not captured by the simplistic picture in Fig. 8), not even the total loss of precipitation could completely compensate for the missing evaporation. In these regions moisture recycling must contribute to the response that follows the suppression of evaporation a priori.

It is probably no coincidence that the South American region around the Tropic of Capricorn and the western coast of southern Africa - the regions where the drying in July seems to be partly attributable to moisture recycling (Sect. 5.1) are located downwind of strong continental moisture-source precipitation minus evaporation

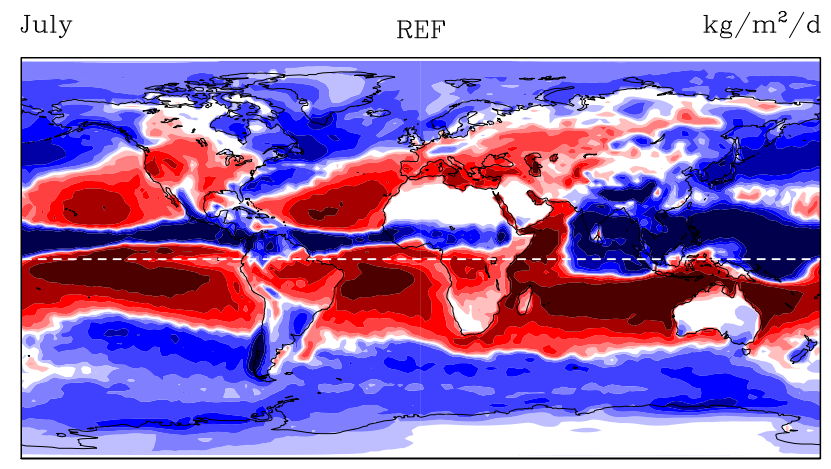
July
DRY
$\mathrm{kg} / \mathrm{m}^{2} / \mathrm{d}$
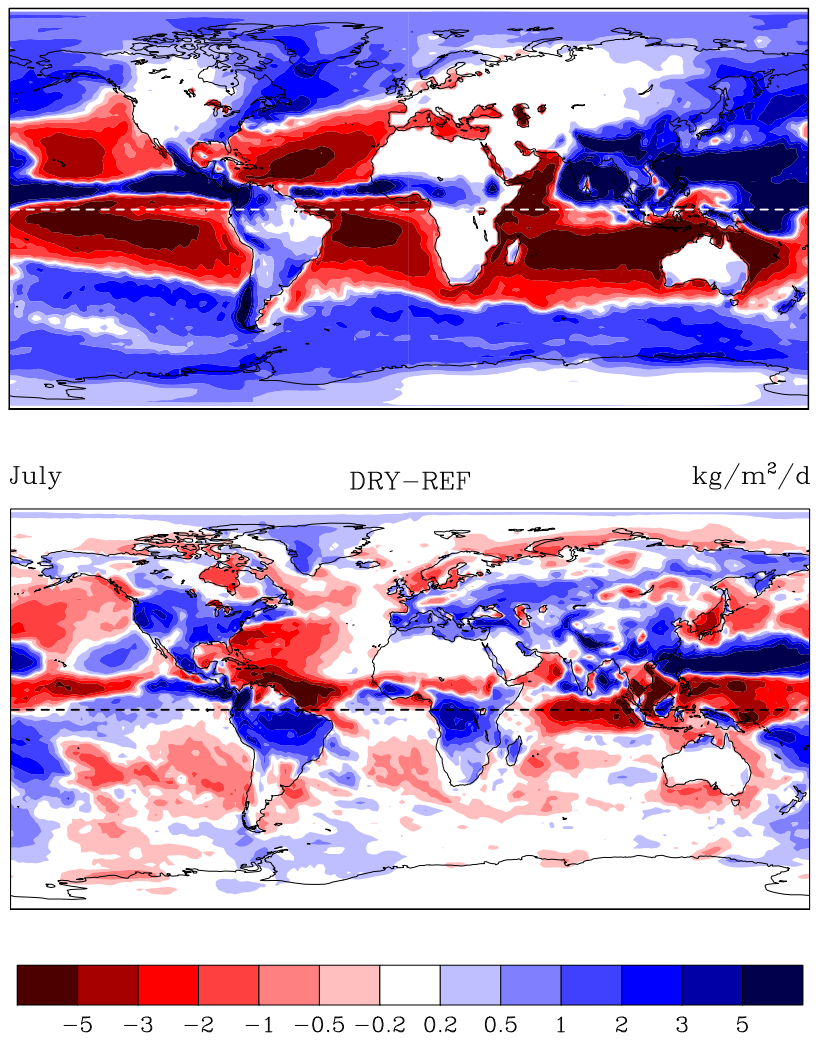

Fig. 9. Precipitation minus evaporation $\left(\mathrm{kg} \mathrm{m}^{-2} \mathrm{~d}^{-1}\right)$ in July in the REF experiment (top panel), in the DRY experiment (middle panel), and the difference between the two (bottom panel). See Fig. S7 in the Supplement for January.

regions. On the other hand, for Eurasia and North America the simplistic picture illustrated in Fig. 8 may partly explain why there are no upwind to downwind drying-gradients in response to the suppression of continental evaporation in July, even though we know that a large part of the response is caused by changes in the atmospheric circulation (Sect. 5.2).

Although largely unrealistic for several reasons, the simplistic picture illustrated in Fig. 8 demonstrates in a striking manner that moisture recycling estimates could in principle 


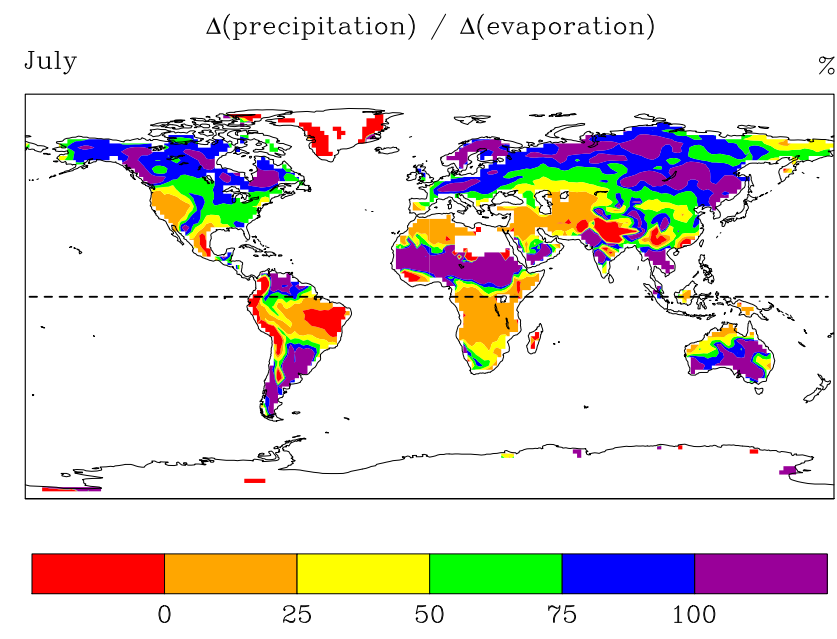

Fig. 10. The response of precipitation in relation to the imposed evaporation decrease $\left(\frac{P_{\mathrm{DRY}}-P_{\mathrm{REF}}}{-\mathrm{REF}}, \%\right)$ in July. Note that $\Delta E=-E_{\mathrm{REF}}$ and $(P-E)_{\mathrm{DRY}}=P_{\mathrm{DRY}}$ because $E_{\mathrm{DRY}}=0$. Violet indicates overcompensation (the land becomes a weaker moisture sink; $\left.P_{\mathrm{DRY}}<(P-E)_{\mathrm{REF}}\right)$, blue, green, yellow and orange indicate incomplete compensation (precipitation still decreases, but the land becomes a stronger moisture sink or weaker moisture source; $\left.(P-E)_{\mathrm{REF}}<P_{\mathrm{DRY}}<P_{\mathrm{REF}}\right)$, and red indicates an amplification of the effect from the evaporation decrease (precipitation increases and thus adds to the evaporation decrease; $P_{\mathrm{DRY}}>P_{\mathrm{REF}}$ ). Continental regions with negative evaporation $(=\mathrm{dew})$ in the REF experiment are left white. See Fig. S8 in the Supplement for January.

be completely useless to predict the consequences of landuse change, even without changes in the atmospheric circulation. While we do not at all claim that the case of "complete" positive local coupling is a prevalent situation in reality, the simplistic picture strongly supports our key argument: moisture recycling estimates have first to be shown to actually tell us something before they can be used to deduce the response of precipitation to land-use change.

Finally, it seems worth to mention that, ignoring the high latitudes, regions with particular high compensation in July (Fig. 10) are to some extent spatially correlated with the northern-summer "hot spot" regions in Koster et al. (2004). This supports the idea that some of the precipitation response may be due to local coupling. The obvious mismatch in high latitudes is not surprising given that the "hot spots" in Koster et al. (2004) include the precondition that evaporation is subject to interannual variability.

\section{Discussion}

The MPI-ESM is capable of reproducing the most important aspects of present-day climate (e.g. Hagemann et al., 2006). This does not guarantee that the model behaves realistic under strongly perturbed conditions, as it is the case in our DRY experiment. In particular the part of the response due to local coupling is subject to considerable inter-model variation that probably is largely attributable to the parameterisation of moist convection (see Sect. 2.2). On the other hand we find a very similar response with an alternative moist convection scheme. Since the large-scale circulation is less susceptible to questionable parameterisation schemes it stands to reason that general circulation models are more reliable in this aspect than for local coupling. And indeed, with a comparable setup Shukla and Mintz (1982) find a similar large-scale response. Note however that in the wet-soil case of Shukla and Mintz (1982) the continents are much wetter than in our REF experiment, so that the response they find is even more pronounced. Anyway, our results claim for validation by similar studies using other models.

However, we argue that for the purpose of this case study - to demonstrate that recycling estimates do not necessarily mirror the consequences of changes in evaporation - the realism of the perturbation and the accuracy of the simulated response are not of great relevance. More important is that the perturbation we apply to test the predictive utility of the recycling measure considered in this study, namely the continental recycling ratio, is immediately suggested by its definition. By subjecting the continental recycling ratio to critical scrutiny instead of recycling measures that quantify moisture recycling on a smaller spatial scale (e.g. the local recycling ratio), we approach the question posed in the title from the largest possible scale.

The computed recycling patterns are based on a vertically integrating tracing scheme (Sect. 3.2). It is evident that this simplification introduces some error into the estimates, in particular where the usually stably stratified free atmosphere is seldomly mixed in the vertical through high convection and/or where horizontal winds are substantially sheared in the vertical. The latter is typically not so much the case in the extratropics, where the flow is dominated by cyclones and anticyclones, but may be more relevant closer to the equator. For example in tropical western Africa during northern summer a north-east directed moisture flux in the monsoon layer below $750 \mathrm{hPa}$ is essentially compensated by a reverse flow above $750 \mathrm{hPa}$. The weak horizontal moisture flux remaining after vertical integration presumably results in an overestimation of moisture recycling. However, the errors are acceptably small given the similarity of recycling estimates obtained with (Yoshimura et al., 2004; van der Ent et al., 2010, and this study) and without (Numaguti, 1999; Bosilovich et al., 2002) vertical integration. Furthermore, the focus of our study is on continental-scale patterns, in particular intra-continental upwind to downwind gradients, rather than on accurate regional estimates.

To keep the interpretability of our results as clear as possible, we use identical climatologies of surface albedo, surface roughness, and SSTs in both experiments. The climatic response of the fully dynamical atmosphere-ocean-land system to the suppression of continental evaporation could be considerably different from the response we obtain with our 
more tightly controlled setup. Important missing feedbacks involve for example albedo changes associated with the extent of snow and sea-ice covered areas. However, our setup is not designed to give a most realistic full-dynamics response, but to make a first step in assessing the informativeness of moisture recycling estimates. We have no reason to assume that one or more of the missing feedbacks would change the response in such a way that our conclusions would have to be revised significantly.

Throughout the paper we distinguish three mechanisms by which evaporation affects precipitation (Fig. 1). However, the sharp separation of the mechanisms, in particular of moisture recycling and local coupling, is not beyond question. We argue that moisture recycling acts slowly, i.e. spatiotemporally integrative, by its influence on the (vertically integrated) atmospheric moisture budget. In contrast, local coupling acts fast, i.e. locally, by its influence on the vertical thermal structure of the atmosphere. This point of view seems to conform to Schär et al. (1999) and Seneviratne et al. (2010) (see Sect. 2.4). However, this distinction is not always made so clearly. For example, in Dirmeyer et al. (2009) and in van den Hurk and van Meijgaard (2010) local recycling ratios (more precisely the temporal correlations of local recycling ratios and soil moisture) are used together with other indicators to decide which locations might be susceptible to local land-atmosphere coupling. We think that the conceptual separation of local coupling and moisture recycling might help to better understand the complex interactions between the land and the atmosphere. However, we concede that in reality the two mechanisms may not be as clearly distinguishable as we think.

\section{Summary}

The idea that moisture recycling estimates can be used to indicate the sensitivity of climate to land-use change relies on the condition that the atmospheric response following a perturbation in evaporation is dominated by the "passive" effect of evaporation on the atmospheric moisture budget, i.e. by moisture recycling. We argue that this implicit condition has not sufficiently been examined yet. Besides moisture recycling, changes in evaporation influence climate also through local coupling and changes in the atmospheric circulation (Fig. 1), where the latter two mechanisms are due to the active role water plays in the atmosphere. Since the three mechanisms act on different scales, it stands to reason that their relative importance depends on the spatial scale of the perturbation. In the present study we approach this issue from the largest possible scale by exploring the relation between continental recycling ratios and the response that follows the complete suppression of continental evaporation.

Focussing on July we find that the largest part of the response can be attributed to the atmospheric circulation, which changes largely due to the intensification of the continental thermal lows. A major consequence in the extratropics is that the westerlies over Eurasia and North America are weakened, which in turn results in drier (more continental) conditions in the western parts of these two continents. The fact that the most severe decrease in precipitation is rather sharply restricted to the continents suggests that positive local coupling adds to the continental drying. The continental recycling ratios obtained from the reference experiment reveal that effects due to moisture recycling should affect the eastern (downwind) parts of Eurasia and North America rather than the western (upwind) parts. That the actual (simulated) response does not conform to this expectation suggests that the non-recycling mechanisms dominate the response. However, the magnitude of the overall drying, although occuring in the "wrong" parts of the continents, is probably also due to moisture recycling (or, more precisely, its absence).

Also in the tropics the response to the suppression of continental evaporation is to a large part due to changes in the atmospheric circulation. In contrast to the extratropics, where the surface-pressure distribution alters mainly the strength and the pattern of horizontal atmospheric motions, the tropical response is dominated by changes in the strength and the position of the regions of low-level convergence (the ITCZ). However, in tropical wet-dry climates during the dry season, when these regions are strong moisture sources $(P-E<0)$, we find that the atmosphere in response to the missing surface evaporation becomes progressively drier along the prevailing wind direction. Here it seems that moisture recycling is at least as important as the other mechanisms. Our results thus indicate that, for continental-scale perturbations, in some (tropical) regions moisture recycling estimates may be more useful than in other (extratropical) regions.

\section{Conclusions}

Our case study demonstrates that moisture recycling estimates can not consistently be used as reliable indicators for the sensitivity of precipitation to modified land-evaporation. More specifically our results indicate that the predictive utility of continental recycling ratios is rather limited because other mechanisms than moisture recycling, induced by water's active role in the atmosphere, dominate the response to the suppression of continental evaporation. It may still be that smaller perturbations yield higher correlations between the response one expects from correspondingly defined recycling estimates and the actual (simulated) response - but this hope must be supported by scientific evidence that is currently missing. Specific analyses that build on the principles of our case study while focussing on smaller spatial scales could help to advance our understanding of moisture recycling and its interplay with local coupling and the atmospheric circulation. 
It seems that the range of spatial scales at which the predictive utility of moisture recycling estimates might be high is narrowed not only from the large scale, as our case study demonstrates, but also from the small scale: Studies on local coupling suggest that below $100-1000 \mathrm{~km}$ effects from local coupling dominate the response to land-surface perturbations (see Sect. 2.4). Without further investigations one can only speculate whether at intermediate spatial scales moisture recycling estimates might be informative indicators. Therefore, further modelling studies (and, ultimately, observational studies) are needed to replace speculations by evidence. Our case study does not suffice to answer the question what moisture recycling estimates tell us, but we think that it is a first step towards an answer. Moreover, we hope that our study stimulates a wider discussion on the predictive utility of moisture recycling estimates for the response of precipitation to land-use change.

\section{Supplementary material related to this article is available online at: http://www.hydrol-earth-syst-sci.net/15/3217/2011/ hess-15-3217-2011-supplement.pdf.}

Acknowledgements. We are grateful to Andreas Chlond and Cathy Hohenegger for very helpful comments on the manuscript, and to Sonia Seneviratne and Christoph Schär for fruitful discussions. We are also obliged to Paul Dirmeyer, Ruud van der Ent, and Bart van den Hurk who considerably helped to improve the manuscript in the review process. The model experiments were carried out on the supercomputing system of the German Climate Computation Centre (DKRZ) in Hamburg.

The service charges for this open access publication have been covered by the Max Planck Society.

Edited by: B. van den Hurk

\section{References}

Beljaars, A. C. M., Viterbo, P., Miller, M. J., and Betts, A. K.: The anomalous rainfall over the United States during July 1993: Sensitivity to land surface parameterization and soil moisture anomalies, Mon. Weather Rev., 124, 362-383, 1996.

Benton, G. S., Blackburn, R. T., and Snead, V. O.: The role of the atmosphere in the hydrologic cycle, EOS Trans. AGU, 31, 6173, 1950.

Bosilovich, M. G., Sud, Y., Schubert, S. D., and Walker, G. K.: GEWEX CSE sources of precipitation using GCM water vapor tracers, Global Energy and Water Cycle Experiment NEWS, 3, 6-7, 2002.

Brubaker, K. L., Entekhabi, D., and Eagleson, P. S.: Estimation of continental precipitation recycling, J. Climate, 6, 1077-1089, 1993.

Budyko, M. I.: Climate and Life, Int. Geophys. Ser., 18, 1974.
Burde, G. I.: Bulk recycling models with incomplete vertical mixing, Part I: Conceptual framework and models, J. Climate, 19, 1461-1472, 2006.

Burde, G. I. and Zangvil, A.: The Estimation of Regional Precipitation Recycling, Part II: A New Recycling Model, J. Climate, 14, 2509-2527, 2001.

Dirmeyer, P. A. and Brubaker, K. L.: Characterization of the global hydrologic cycle from a back-trajectory analysis of atmospheric water vapor, J. Hydrometeorol., 8, 20-37, 2007.

Dirmeyer, P. A., Koster, R. D., and Guo, Z.: Do global models properly represent the feedback between land and atmosphere?, J. Hydrometeorol., 7, 1177-1198, 2006.

Dirmeyer, P. A., Schlosser, C. A., and Brubaker, K. L.: Precipitation, recycling, and land memory: An integrated analysis, J. Hydrometeorol., 10, 278-288, 2009.

Eltahir, E. A. B. and Bras, R. L.: Precipitation recycling in the Amazon basin, Q. J. Roy. Meteorol. Soc., 120, 861-880, 1994.

Findell, K. L. and Eltahir, E. A. B.: An analysis of the soil moisturerainfall feedback, based on direct observations from Illinois, Water Resour. Res., 33, 725-735, 1997.

Findell, K. L. and Eltahir, E. A. B.: Atmospheric controls on soil moisture-boundary layer interactions, Part I: Framework development, J. Hydrometeorol., 4, 552-569, 2003a.

Findell, K. L. and Eltahir, E. A. B.: Atmospheric controls on soil moisture-boundary layer interactions. Part II: Feedbacks within the continental United States, J. Hydrometeorol., 4, 570-583, 2003b.

Findell, K. L., Gentine, P., Lintner, B. R., and Kerr, C.: Probability of afternoon precipitation in eastern United States and Mexico enhanced by high evaporation, Nat. Geosci., 4, 434-439, 2011.

Fitzmaurice, J. A.: A critical analysis of bulk precipitation recycling models, Ph.D. thesis, Massachusetts Institute of Technology, 2007.

Hagemann, S., Arpe, K., and Roeckner, E.: Evaluation of the Hydrological Cycle in the ECHAM5 Model, J. Climate, 19, 38103827, 2006.

Hohenegger, C., Brockhaus, P., Bretherton, C. S., and Schaer, C.: The soil moisture-precipitation feedback in simulations with explicit and parameterized convection, J. Climate, 22, 5003-5020, 2009.

Kleidon, A. and Heimann, M.: Assessing the role of deep rooted vegetation in the climate system with model simulations: mechanism, comparison to observations and implications for Amazonian deforestation, Clim. Dynam., 16, 183-199, 2000.

Koster, R. D., Dirmeyer, P. A., Guo, Z., Bonan, G., Chan, E., Cox, P., Gordon, C. T., Kanae, S., Kowalczyk, E., Lawrence, D., Liu, P., Lu, C. H., Malyshev, S., McAvaney, B., Mitchell, K., Mocko, D., Oki, T., Oleson, K., Pitman, A., Sud, Y. C., Taylor, C. M., Verseghy, D., Vasic, R., Xue, Y., and Yamada, T.: Regions of strong coupling between soil moisture and precipitation, Science, 305, 1138, doi:10.1126/science.1100217, 2004.

Lettau, H., Lettau, K., and Molion, L. C. B.: Amazonia's Hydrologic Cycle and the Role of Atmospheric Recycling in Assessing Deforestation Effects, Mon. Weather Rev., 107, 227-238, 1979.

Nordeng, T. E.: Extended versions of the convection parametrization scheme at ECMWF and their impact upon the mean climate and transient activity of the model in the tropics, Tech. rep., Research Department Technical Memorandum, ECMWF, Reading, UK, 1994. 
Numaguti, A.: Origin and recycling processes of precipitating water over the Eurasian continent: Experiments using an atmospheric general circulation model, J. Geophys. Res., 104, 1957-1972, 1999.

Pal, J. S. and Eltahir, E. A. B.: Pathways relating soil moisture conditions to future summer rainfall within a model of the landatmosphere system, J. Climate, 14, 1227-1242, 2001.

Press, W. H., Teukolsky, S. A., Vetterling, W. T., and Flannery, B. P.: Numerical recipes: the art of scientific computing, Cambridge Univ. Pr., 2007.

Raddatz, T. J., Reick, C., Knorr, W., Kattge, J., Roeckner, E., Schnur, R., Schnitzler, K. G., Wetzel, P., and Jungclaus, J.: Will the tropical land biosphere dominate the climate-carbon cycle feedback during the twenty-first century?, Clim. Dynam., 29, 565-574, 2007.

Roeckner, E., Baeuml, G., Bonaventura, L., Brokopf, R., Esch, M., Giorgetta, M., Hagemann, S., Kirchner, I., Kornblueh, L., Manzini, E., Rhodin, A., Schlese, U., Schulweida, U., and Tompkins, A.: The atmospheric general circulation model ECHAM5, Part I: Model description, Tech. Rep. 349, Max Planck Institute for Meteorology, Hamburg, Germany, 2003.

Rowntree, P. R. and Bolton, J. A.: Simulation of the atmospheric response to soil moisture anomalies over Europe, Q. J. Roy. Meteorol. Soc., 109, 501-526, 1983.

Saeed, F., Hagemann, S., and Jacob, D.: Impact of irrigation on the South Asian summer monsoon, Geophys. Res. Lett., 36, L20711, doi:10.1029/2009GL040625, 2009.

Salvucci, G. D., Saleem, J. A., and Kaufmann, R.: Investigating soil moisture feedbacks on precipitation with tests of Granger causality, Adv. Water Res., 25, 1305-1312, 2002.

Savenije, H. H. G.: New definitions for moisture recycling and the relation with land-use changes in the Sahel, J. Hydrol., 167, 5778, 1995.

Schär, C., Luethi, D., Beyerle, U., and Heise, E.: The soilprecipitation feedback: A process study with a regional climate model, J. Climate, 12, 722-741, 1999.
Seneviratne, S. I., Corti, T., Davin, E. L., Hirschi, M., Jaeger, E. B., Lehner, I., Orlowsky, B., and Teuling, A. J.: Investigating soil moisture-climate interactions in a changing climate: A review, Earth-Sci. Rev., 99, 125-161, 2010.

Shukla, J. and Mintz, Y.: Influence of land-surface evapotranspiration on the Earth's climate, Science, 215, 1498-1501, 1982.

Taylor, C. M., Parker, D. J., and Harris, P. P.: An observational case study of mesoscale atmospheric circulations induced by soil moisture, Geophys. Res. Lett., 34, L15801, doi:10.1029/2007GL030572, 2007.

Taylor, C. M., Gounou, A., Guichard, F., Harris, P. P., Ellis, R. J., Couvreux, F., and De Kauwe, M.: Frequency of Sahelian storm initiation enhanced over mesoscale soil-moisture patterns, Nat. Geosci., 4, 430-433, 2011.

Tiedtke, M.: A comprehensive mass flux scheme for cumulus parameterization in large-scale models, Mon. Weather Rev., 117, 1779-1800, 1989.

Trenberth, K. E.: Atmospheric Moisture Recycling: Role of Advection and Local Evaporation, J. Climate, 12, 1368-1381, 1999.

van den Hurk, B. J. J. M. and Blyth, E.: WATCH/LoCo Workshop, 25-27 June 2008, De Bilt, The Netherlands, GEWEX news, 12 $14,2008$.

van den Hurk, B. J. J. M. and van Meijgaard, E.: Diagnosing landatmosphere interaction from a regional climate model simulation over West Africa, J. Hydrometeorol., 11, 467-481, 2010.

van der Ent, R. J. and Savenije, H. H. G.: Length and time scales of atmospheric moisture recycling, Atmos. Chem. Phys., 11, 18531863, doi:10.5194/acp-11-1853-2011, 2011.

van der Ent, R. J., Savenije, H. H. G., Schaefli, B., and Steele-Dunne, S. C.: Origin and fate of atmospheric moisture over continents, Water Resour. Res., 46, W09525, doi:10.1029/2010WR009127, 2010.

Yoshimura, K., Oki, T., Ohte, N., and Kanae, S.: Colored moisture analysis estimates of variations in 1998 Asian monsoon water sources, J. Meteorol. Soc. Jpn., 82, 1315-1329, 2004. 